\title{
Role of phosphodiesterase 5 in synaptic plasticity and memory
}

\author{
Daniela Puzzo',2 \\ Salvatore Sapienza' \\ Ottavio Arancio ${ }^{2}$ \\ Agostino Palmeri'
}

'Dept of Physiological Sciences, University of Catania, Catania, Italy; ${ }^{2}$ Dept of Pathology, Taub Institute for Research on Alzheimer's Disease and the Aging Brain, Columbia University, New York, NY, USA
Correspondence: Daniela Puzzo Dipartimento di Scienze Fisiologiche, Viale A. Doria 6, Ed. 2, 95।25,

Catania, Italy

Tel +390957384262

Fax +39095330645

Email danypuzzo@yahoo.it

\begin{abstract}
Phosphodiesterases (PDEs) are enzymes that break down the phosphodiesteric bond of the cyclic nucleotides, cAMP and cGMP, second messengers that regulate many biological processes. PDEs participate in the regulation of signal transduction by means of a fine regulation of cyclic nucleotides so that the response to cell stimuli is both specific and activates the correct third messengers. Several PDE inhibitors have been developed and used as therapeutic agents because they increase cyclic nucleotide levels by blocking the PDE function. In particular, sildenafil, an inhibitor of PDE5, has been mainly used in the treatment of erectile dysfunction but is now also utilized against pulmonary hypertension. This review examines the physiological role of PDE5 in synaptic plasticity and memory and the use of PDE5 inhibitors as possible therapeutic agents against disorders of the central nervous system (CNS).
\end{abstract}

Keywords: phosphodiesterase 5, NO/cGMP pathway, sildenafil, synaptic plasticity, memory, Alzheimer's disease

\section{Phosphodiesterases Introduction}

The cyclic nucleotides, cAMP and cGMP are second messengers that regulate signal transduction in various biological systems. They respond to extracellular signals (neurotransmitters, hormones, olfactive and luminous signals) and activate intracellular targets such as ion channels, kinases, and transcription factors that trigger the cellular response to the message. The extracellular signal is thus transferred by the cyclic nucleotides to one of the effector proteins, the most important of these are protein kinase A (PKA) and protein kinase G (PKG) that, in turn, phosphorylate other enzymes or transcription factors (Figure 1).

The levels of cAMP and cGMP are maintained thanks to a balance between production, carried out by adenyl cyclase (AC) and guanylyl cyclase (GC), and destruction, carried out by phosphodiesterases (PDEs) (Figure 1). PDEs regulate the nucleotide signal both in amplitude and duration (spatial and temporal regulation) and modulate the "cross talk" between various second messengers. For example many effects of $\mathrm{Ca}^{2+}$ on cAMP and cGMP are mediated by the activation of the $\mathrm{Ca}^{2+}-\mathrm{Calmodulin}\left(\mathrm{Ca}^{2+}-\mathrm{CaM}\right)$ dependent phosphorylation of PDEs (Sonnenburg et al 1995).

Over the last few years there has been an increasing number of studies on PDEs. This is also thanks to the potential use of these enzymes as targets of drugs that can regulate the levels of cyclic nucleotides and the various physiological functions connected to them. The recognition of the therapeutic potential of PDEs stems from the ubiquitous nature of the second messengers on which these enzymes act. Notwithstanding the great potential of these inhibitors, the only pathologies currently treated with PDE inhibitors are erectile dysfunction and, more recently, pulmonary hypertension. This is due to the complexity of the PDE family and the selectivity of the inhibitors used. Various studies are now focusing on the role of PDEs in the CNS and on the potential 


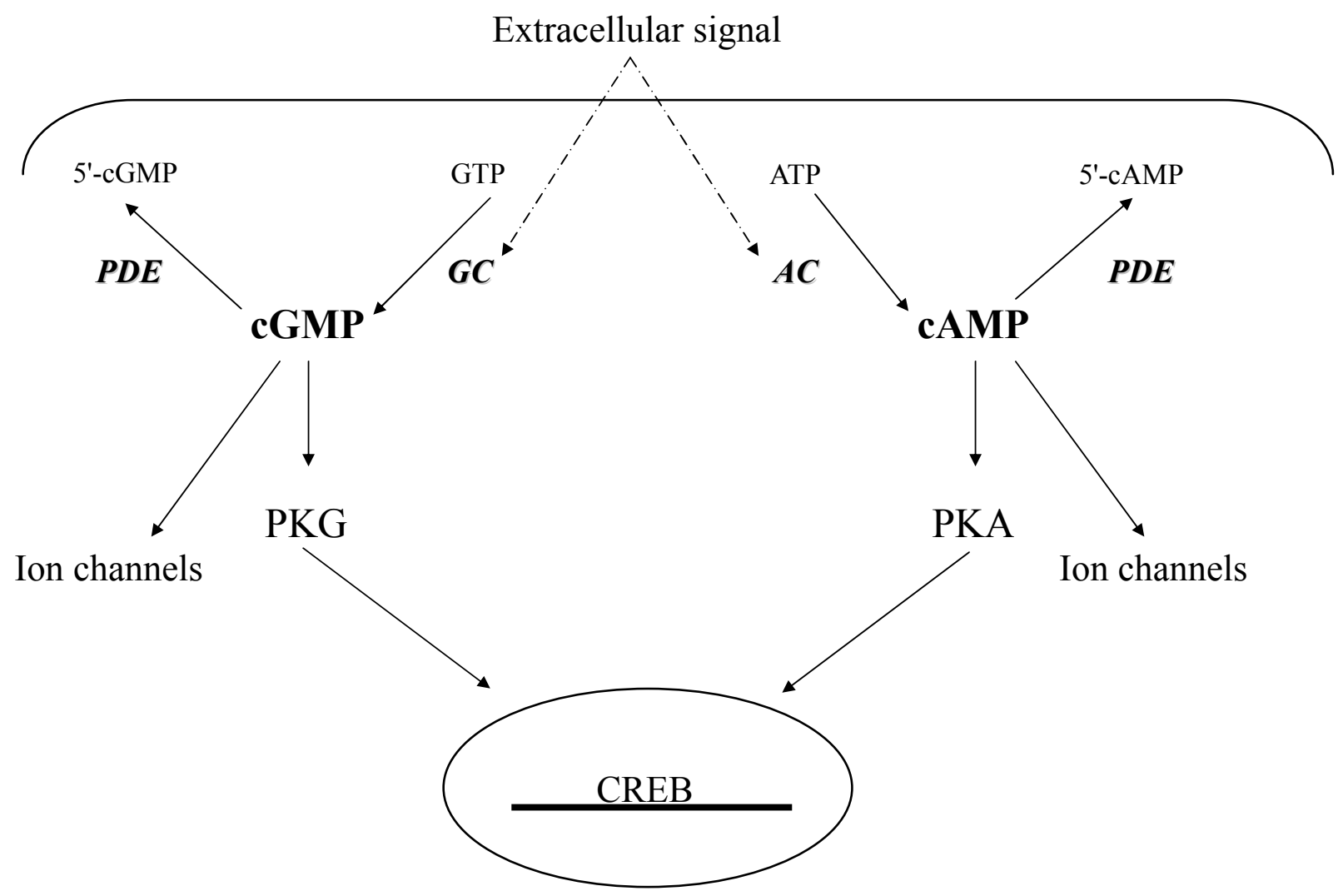

Figure I Cyclic nucleotide signal. The extracellular signal (neurotransmitters, hormones, olfactive and luminous signals) is transferred by the cyclic nucleotides cAMP and cGMP to one of the effector proteins, the most important of these are ion channels, protein kinase A (PKA) and protein kinase G (PKG). The kinases, in turn, phosphorylate other enzymes or transcription factors such as CREB in the nucleus. Cyclic nucleotides levels are maintained through a balance between production, carried out by adenyl cyclase (AC) and guanylil cyclase (GC) from ATP and GTP, respectively, and destruction, carried out by phosphodiesterases (PDEs) that lead to the formation of the inactive forms 5'AMP and 5'GMP.

use of PDE inhibitors for nervous system disorders. This can be explained by the presence of PDEs in various regions of the CNS (Ariano and Appleman 1979; Shinozawa and Bitensky 1981; Epplen et al 1982; Shotwell 1983; Kariya and Dage 1988; Repaske et al 1993; Lobban et al 1994; Polli and Kincaid 1994; Yan et al 1994; Lal et al 1996; Cherry and Davis 1999; Shakur et al 2000; Andreeva et al 2001; D'Sa et al 2002; Suvarna and O'Donnel 2002; van Staveren et al 2002; Houslay and Adams 2003; Kobayashi et al 2003; Noyama and Maekawa 2003; Pitts et al 2004; Reyes-Irisarri et al 2005) and to the fact that cAMP and cGMP have been recognized as secondary messengers of various neuronal phenomena such as synaptic plasticity (Dismukes and Daly 1976; Kandel and Schwartz 1982; Yovell et al 1987; Dixon and Atwood 1989; Storozhuk and Balaban 1990; Shibuki and Okada 1991; Zhong and Wu 1991; Zhong et al 1992; Arancio et al 1995; Wu et al 1995; Southam et al 1996; Lu et al 1999; Renger et al 2000; Yoshimura and Kato 2000; Bon and Garthwaite 2001, 2003; Esteban et al 2003; Waltereit and Weller 2003; Wang and Storm 2003; Barnstable et al
2004; Feil et al 2005; Makhinson et al 2006; Liu et al 2007; Wu et al 2007).

\section{Background}

The activity of PDEs was described for the first time in 1886, when Dr Henry Hyde Salter noted that caffeine had bronchodilator properties (Boswell-Smith et al 2006). In 1958, Sutherland and Rall first identified the nucleotide cAMP in liver extracts as a second messenger and suggested that it could mediate several cellular effects of neurotransmitters and hormones (Sutherland 1958). The existence of an enzymatic activity able to catalyze the degradation of this molecule was used as one of the initial processes supporting the evidence that cAMP is a relevant molecule from the physiological point of view (Sutherland 1958). Indeed, Sutherland and colleagues discovered that glucagon and catecholamines act in the liver by increasing the concentrations of cAMP and that the effect of caffeine on glucagon involved the inhibition of cAMP-dependent PDEs (Berthet et al 1957; Rall and Sutherland 1958; Butcher and Sutherland 
1962; Exton et al 1971). In 1970 PDEs were differentiated in rat and bovine tissue and it was demonstrated that the specificity of the reaction was due to the hydrolysis of the cAMP and cGMP phosphoester bond (Beavo et al 1970). With the development of radionucleotides it was possible to measure PDE activity at the substrate level at nearly physiological concentrations. From then various PDEs have been isolated, purified and characterized.

\section{Classification}

The superfamily of PDEs is divided into three principle classes I, II and III, having different sequences. Class I includes all the mammal PDEs (Francis et al 2000) as well as Drosophila (Chen et al 1986), Caenorhabditis (Koyanagi et al 1998), and yeast (Sass et al 1986, Thomasn et al 1998). These enzymes are produced by different genes (Beavo et al 1994; Fisher et al 1998) and show high affinity for the cGMP and /or cAMP molecule. Class II includes enzymes from fungi such as Saccharomyces cerevisae (Nikawa et al 1987), Dictyostelium discoideum (Lacombe et al 1986), Schizosaccharomyzes pombe (DeVoti et al 1991), Candida albicans (Hoyer et al 1994) and one from bacteria, Vibrio fischeri (Dunlap and Callahan 1993). PDE class II shares a conserved motif containing three histidine residues that may be part of a metal ion binding site such as $\mathrm{Zn}^{2+}$ for Vibrio fischeri (Callahan et al 1995). Class III includes only enzymes from prokaryotes such as Escherichia coli (Richter 2002). Given that the catalytic site of PDE class III is comparable to the purple acid phosphatases, these enzymes could be considered as members of a large family of structurally related dimetallophosphoesterases (Richter 2002).

Twenty-one classes of genes and diverse spliced transcriptional variants for the PDE class I of humans, rats and mice have been identified. They have been classified into 11 families based on particular subcellular distributions, structural similarities, mechanisms of regulation, amino acid sequences, proteic domains and enzymatic properties among which are specificity for the substrate, kinetic proprieties, and sensitivity to endogenous regulators and inhibitors.

Some PDEs are highly specific for cAMP (PDE4, PDE7, PDE8); others are highly specific for cGMP (PDE5, PDE6, PDE9), and some have mixed specificity (PDE1, PDE2, PDE3, PDE10). The nomenclature assigns an Arabic number to each family with an individual gene expressed by a letter and every spliced variant of the gene is identified by a number (ie, PDE5A1).

\section{Structure and mechanism of action}

All PDEs are dimeric though the importance of this structure is not well known. Each has a core of 270 amino acids with a high degree of conservation (25\%-35\%) among the various families that is localized at the $\mathrm{C}$-term and contains the catalytic domain of the enzyme. Within each family, the sequence of the catalytic domain is highly conserved $(>75 \%)$. This makes the identification of the inhibitors of the active site possible and distinguishable between the different families, with the exception of the very high homology between PDE5 and PDE11 that makes, for example, some inhibitors of PDE5 such as tadalafil also active against PDE11 (Weeks et al 2005).

Most PDEs have a regulatory domain at the N-term that varies among the families and provides the sites for dimerization, phosphorylation and modulatory bonds such as $\mathrm{Ca}^{2+}-\mathrm{CaM}$ and cGMP. For example, PDE1 contains a $\mathrm{Ca}^{2+} / \mathrm{CaM}$-binding domain that activates the enzyme. About half of the genetic families have a GAF domain (PDE2, PDE5, PDE6, PDE10, PDE11) that mediates the allosteric regulation of the bond with cGMP. The other PDEs belong to NON-GAF-PDEs. It is believed that some PDEs also possess an auto-inhibitory domain in the structure of the enzyme that is detected by some PDE activators (Jin et al 1992; Sonnenburg et al 1995).

PDEs are ubiquitously distributed and most of them have been found in CNS (for a review see Bender and Beavo 2006). The cGMP-hydrolysing PDE2, PDE5, and PDE9 and the cAMP-hydrolysing PDE4 and PDE7 are located in the hippocampus where they are likely to be involved in memory and/or long-term potentiation (LTP; Beavo 1995; Barad et al 1998; Houslay 2001; Mirò et al 2001; Boess et al 2004; Gong et al 2004; Van Staveren et al 2004; Wunder et al 2005; Reyes-Irisarri et al 2005). PDE6 has also been found in the hippocampus, although it does not affect synaptic transmission or synaptic plasticity (Kuenzi et al 2003).

PDEs hydrolyze the phosphodiesteric bond of cyclic nucleotides between the atoms of phosphorus and oxygen in position 3' with the inversion of the phosphorus atom configuration (Burgers et al 1979; Goldberg et al 1980) and the consequent formation of adenosin monophosphate (AMP) and guanosin monophosphate (GMP), which are recycled as substrates for the formation of ATP and GTP.

PDEs are regulated by means of 3 principal mechanisms: i) Availability of the substrate, such as the stimulation of PDE activity after the increase of the levels of cyclic nucleotides or after alteration of the ratio of hydrolysis between one nucleotide and another; ii) Regulation of the intracellular signal 
by extracellular signals (ie, phosphorylation); iii) Feedback regulation (Corbin and Francis 1999).

\section{Phosphodiesterase 5}

\section{Characteristics}

PDE5 is a cGMP-specific enzyme that hydrolyzes cGMP. The cyclic nucleotid plays a fundamental role in signal translation. It stimulates the relaxation of smooth muscle, the degranulation of neutrophils, inhibits platelet aggregation and initiates translation of the visual signal (Furchgott and Vanhoutte 1989; Hofmann et al 1992; Lincoln and Cornwell 1993; Garbers and Lowe 1994; Moro et al 1996; Lohmann et al 1997; Corbin and Francis 1999). cGMP is one of the targets for the action of nitric oxide (NO), a particular neurotransmitter, which is the main subject of this review.

As mentioned above, the tissue levels of cGMP depend on the balance between the activity of GC that catalyzes the formation of cGMP from GTP, and from PDEs that catalyze the breakdown of cGMP into GMP.

PDE5 was purified in 1980 by Francis and colleagues from rat lungs (Francis et al 1980; Francis and Corbin 1988) and cloned in 1993 by McAllister-Lucas (McAllister-Lucas et al 1993). Two spliced variants have been recognized (Loughney et al 1998; Yanaka et al 1998). At first it was believed that PDE5 was part of PDE6 (PDE of the photoreceptors) given its notable similarity. However, considering that the sequence identity is less than 60\% (McAllister-Lucas 1993), PDE5 was subsequently classified as a separate family.

The tissue distribution of PDE5 generally coincides with that of PKG, probably because both enzymes are the principal intracellular receptors of cGMP. Moreover, PKG is an excellent in vitro catalyst for the phosphorylation of PDE5 (Thomas et al 1990). PDE5 has a typical cytosolic localization with high levels in smooth muscle, platelets, kidney and in some zones of the CNS (Francis and Corbin 1999; Kotera et al 2000; van Staveren et al 2004; Dolci et al 2006; Menniti et al 2006).

\section{The NO/cGMP pathway}

To understand the function of PDEs it is necessary to know the pathway by which they act. cGMP is produced by the GC enzyme, an NO target. NO is a molecule that has been widely studied since 1800 , when the potential therapeutic role of nitroglycerin with its vasodilatatory effect was discovered for the treatment of angina pectoris (Brunton 1867). It was later discovered that the effect of $\mathrm{NO}$ was mediated through cGMP synthesis, which activated vascular reactions. NO was identified in the nervous system in 1988 as a molecule that was able to mediate the increase of cGMP after the activation of the glutamatergic receptor N-methyl-D-aspartate (NMDA) (Garthwaite and Boulton 1995).

Over the last few years the function of NO as a neurotransmitter has been studied (Puzzo et al 2006). A particular characteristic is its capacity to function as a retrograde neurotransmitter able to transfer information from the post- to the pre-synaptic terminal. This completely revolutionized the concept of synaptic transmission and neuronal communication.

The formation of NO is catalyzed by the NO synthase enzyme (NOS) of which different variants exist: i) the $\mathrm{Ca}^{2+}$ dependent constitutive form (c-NOS), consisting of the endothelial form (e-NOS) or type III and the neuronal form (n-NOS) or type I, present in the endothelium, and in glial and neuronal cells that produce $\mathrm{NO}$ in physiological conditions; ii) the $\mathrm{Ca}^{2+}$-independent inducible form (i-NOS) or type II, present in macrophages, hepatocytes, smooth muscle, glia and endothelium that produces NO following immunological stimuli (ie, interferon $\gamma$, tumor necrosis factor $\alpha$, LPS).

The biological receptor of NO is GC, a ubiquitous enzyme that, once activated, catalyzes the formation of cGMP. cGMP has various targets among which are cGMP-dependent channels, PKG, and PDEs. PKG are mediators of signal translation (Lohmann 1997). PKGI, composed of the $\alpha$ and $\beta$ subunits, is ubiquitous; the monomeric PKGII is expressed in various tissues such as the lung, kidney, testicle and brain. cGMP can also activate the cAMP pathway acting on the cAMP binding site and PKA (Tsukada et al 2002).

\section{Structure and function of PDE5}

The human gene for PDE5 has been mapped in the $4 \mathrm{q} 26$ chromosome, which contains 24 exons that occupy approximately $100 \mathrm{k}$ bases (Yanaka et al 1998). The enzyme PDE5 is an active homodimer, with an MW of $\sim 3000 \mathrm{kd}$ (Figure 2). Each monomer contains a catalytic domain in the C-term with 2 binding sites for $\mathrm{Zn}^{2+}$. These are involved in the process of catalysis and it is believed that the catalytic activity of PDE 4, 5 and 6 is sustained by submicromolar concentrations of $\mathrm{Zn}^{2+}$ (Francis et al 1994; Percival et al 1997; He et al 2000). In the C-term catalytic domain there is an allosteric binding site for cGMP and in the N-term regulatory domain there are two allosteric binding sites called GAF a and b domains (McAllister-Lucas et al 1995). It is likely that GAFa is responsible for the allosteric binding of cGMP (Liu et al 2002; Zoraghi et al 2005). Both the allosteric and catalytic sites are highly specific for cGMP. The catalytic domain has high affinity for cGMP $(\mathrm{Km} \sim 1-5 \mu \mathrm{M}$, compared with $\mathrm{Km} \sim 300 \mu \mathrm{m}$ of 


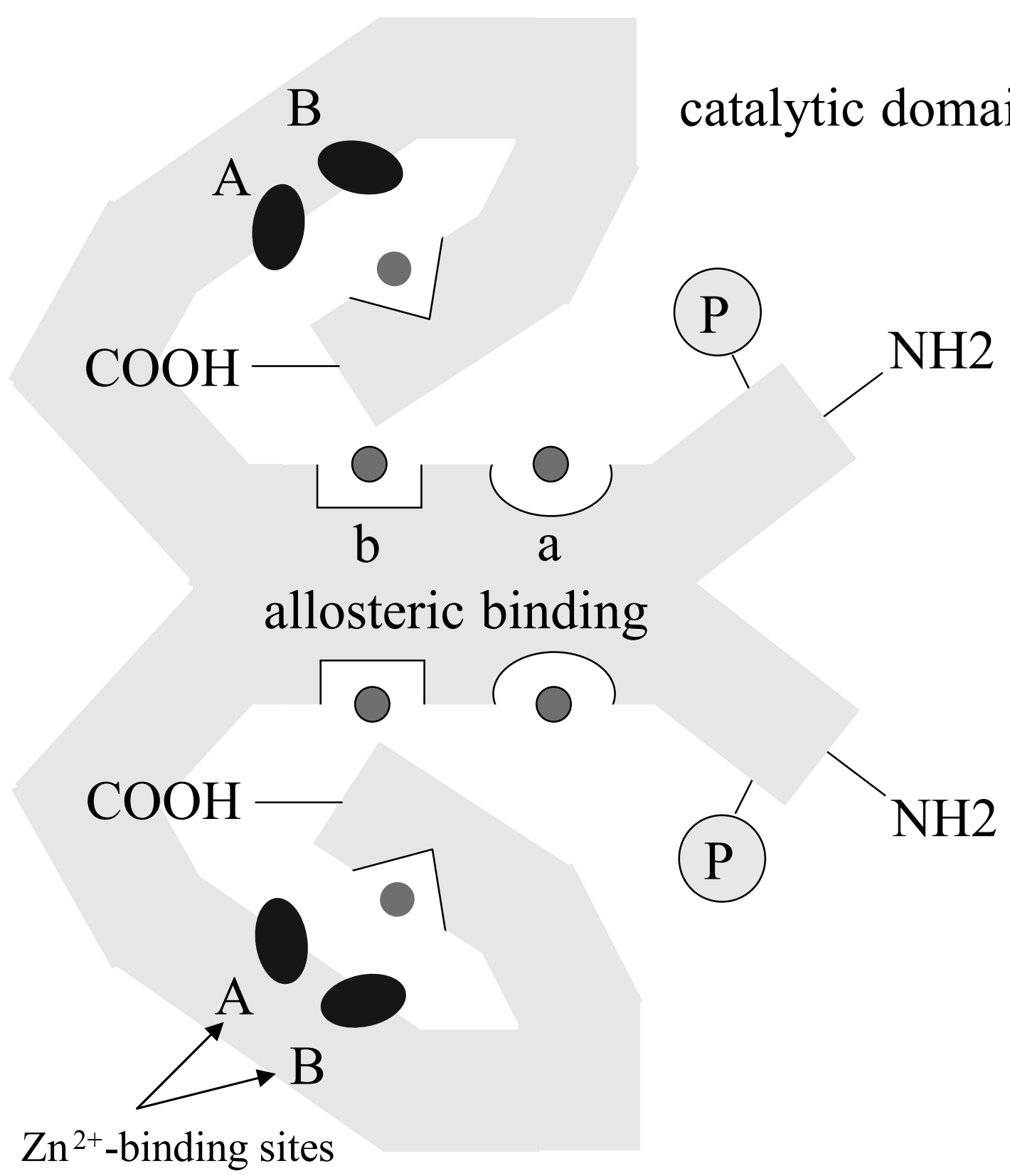

Figure 2 Schematic representation of PDE5 structure. PDE5 is a homodimer containing, in each monomer, a C-term catalytic domain and an N-term regulatory domain. The catalytic domain contains $2 \mathrm{Zn}^{2+}$-binding sites (A and B) and an allosteric binding site for cGMP.The regulatory domain contains two allosteric binding sites called GAF a and b, domains responsible for the allosteric binding of cGMP.The occupation of the allosteric site by cGMP is necessary for the specific phosphorylation of Ser-92 by PKG.

cAMP). Binding of cGMP to the allosteric site is necessary for the specific phosphorylation of Ser-92 by PKG. The bond not only activates the catalytic function but increases the binding affinity for cGMP (Corbin et al 2000; Francis et al 2002; Zoraghi et al 2005). The two allosteric sites homologous for cGMP ( $a$ and $b$ ) are kinetically distinct. Both sites need to bind to cGMP for PDE activation. The increased interaction of cGMP with the catalytic site increases the binding of cGMP in the allosteric site thus increasing the phosphorylation of the enzyme promoting a further increase of cGMP cleavage.
There are three isoforms of PDE5 (PDE5A1-PDE5A3) which are distinguished based on their $\mathrm{N}$-term sequence. PDE5A1 and PDE5A2 are ubiquitous, but PDE5A3 is specific to smooth muscle (Lin 2004). A single PDE5A gene encodes for the 3 isoforms and the initial three exons (A1-A3-A2) encode the isoform-specific sequences. The promoters are responsive to cGMP or cAMP stimulation, and several studies have demonstrated regulation of PDE5 expression possibly through these promoters (Lin et al 2006). The potential role of different PDE5A promoters in 
the effect of PDE5 inhibitors is currently being investigated (Lin 2004). Moreover, the study of the 3 isoforms may be relevant for future drug development as our knowledge of PDE structure-function relations increases.

The principal functions of PDE5 consist of modulating hemodynamics affecting the contracted state of vessel cells by regulating the phasic nature of smooth muscle physiology (Jackson et al 1999; Rybalkin et al 2003; Prisant 2006; Cawley et al 2007). PDE5 exerts its action in all smooth muscle districts modulating, other then the tone of blood vessels, the contractile state of organs such as the penis, uterus, and intestines. However, its function has been mainly studied in the corpora cavernosa and in the pulmonary system given the therapeutical implication of the use of PDE5 inhibitors aimed at provoking a relaxation of these organs to alleviate erectile dysfunction and pulmonary hypertension (Ziegler et al 1995; Cohen et al 1996;
Weimann et al 2000; Lewis and Semigran 2004; Toward et al 2004; Larrue et al 2005). PDE5 plays also a key role in the peripheral vessel system by regulating systemic blood pressure. Moreover, PDE5 is involved in the regulation of the response to the atrial natriuretic peptide (ANF) (Weishaar et al 1990) and it might regulate $\mathrm{Na}^{+}$retention (Ghali-Ghoul et al 2007).

Figure 3 shows the effects exerted by cGMP in some target organs and the possible therapeutical application of PDE5 inhibitors leading to an increase of cGMP.

\section{PDE5 Inhibitors}

\section{Sildenafil and other PDE5 inhibitors}

For many years, nonselective PDE5 inhibitors such as caffeine, theophylline and IBMX have been used to investigate the physiological effects of cyclic nucleotides. A more selective inhibitor called sildenafil has now attracted

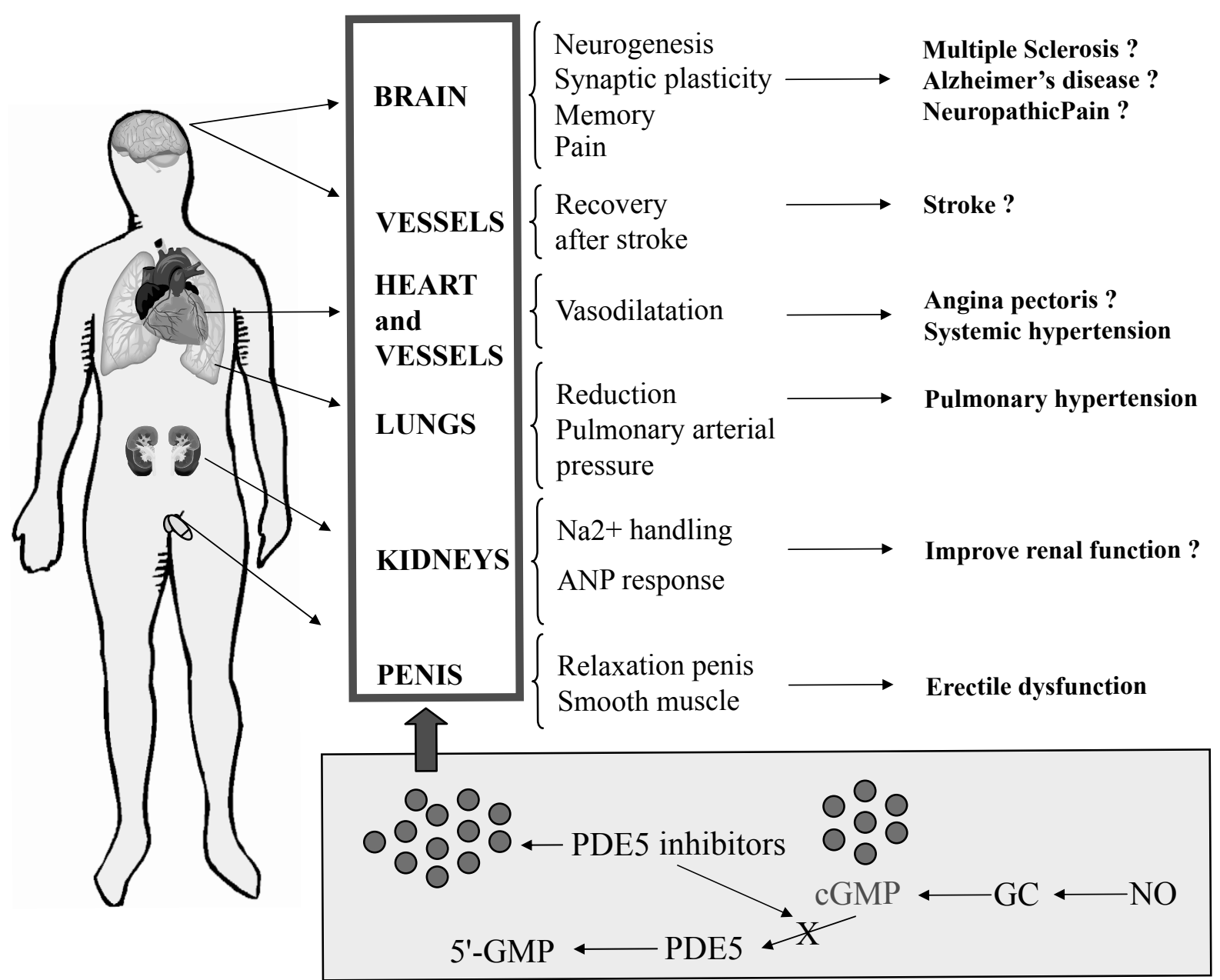

Figure 3 cGMP functions and possible therapeutic use of PDE5 inhibitors. PDE5 inhibitors block the degradation of cGMP (bottom panel) leading to an increase of the level of cGMP that can exert its action on several target organs. On the right side, both the approved and possible (question mark) therapeutical applications of PDE5 inhibitors in humans. 
the attention of many researchers. Sildenafil is the active agent of the widely diffused drug Viagra used for erectile dysfunction (ED).

Sildenafil, initially synthesized with the aim of treating arterial hypertension and angina pectoris, was the first drug approved by the USA Food and Drug Administration for the treatment of ED (FDA 1998). To date it is the principle treatment for ED given its risk-benefit ratio. Sildenafil, with the commercial name of Revatio (Pfizer), was also approved for the therapy of hypertension of the pulmonary artery in June 2005. Various studies indicate that sildenafil can offer new strategies for the treatment of other pathologies such as multiple sclerosis (MS), pain, and memory loss (Uthayathas et al 2007).

Thanks to these discoveries, thousands of compounds have been synthesized and screened against PDE5. Reported PDE5 inhibitors can be divided into the following classes: 1) cGMP-based, represented by sildenafil (Viagra) and vardenafil (Levitra) (Pfizer, Bayer, Sheering-Plough), 2) $\beta$-carboline - derived, represented by tadalafil (Cialis) (Lilly, Johnson\&Johnson [J\&J], 3) quinazoline and isoquinolinone derivatives (Bristol-Myers-Squibb [BMS], Japan), and 4) phthalazine derivatives (BMS, Japan).

Among these vardenafil and tadalafil are considered the most potent inhibitors (Kulkarni and Patil 2004). Vardenafil is a new drug used for erectile dysfunction. It has an IC50 of $0.7 \mathrm{nM}$ for PDE5 with respect to other PDEs (PDE1: $180 \mathrm{~nm}$; PDE2, 3, $4>1 \mu \mathrm{m}$; PDE6: $11 \mathrm{~nm}$ ) (Saenz de Tejada et al 2001). The inhibitory potential of vardenafil towards PDE5 is 5 times greater than sildenafil.

Differently than sildenafil and vardenafil, which are cGMP-based inhibitors, tadalafil is a $\beta$-carboline-derived drug with no effect on PDE1 (selectivity ratio > 2000) and on PDE6 (selectivity ratio 1000), and an IC50 against PDE5 of $5.0 \mathrm{nM}$ (Daugan et al 2003). Tadalafil is a second generation oral drug. It acts quickly and its effects last longer than sildenafil (Forgue et al 2006).

Sildenafil, vardenafil, and tadalafil are rapidly absorbed in the gastrointestinal tract at the level of the small intestine. The half life of sildenafil and vardenafil is $\sim 3-4 \mathrm{~h}$ whereas tadalafil has a half-life of $\sim 18$ h (Kulkarni and Patil 2004; Forgue et al 2006). They are all metabolized by means of the p450 cytochrome system and also eliminated by this system at the hepatic level.

The possible use of these drugs in the CNS is also related to their ability to cross the blood - brain barrier (BBB). Sildenafil is reported to clearly cross the BBB (FDA 1998). Evidence for the ability of vardenafil to cross the BBB is indirect (Prickaerts et al 2004), and tadalafil is unlikely to cross it (personal communication from $\mathrm{V}$. Florio at Icos).

These drugs can have side effects such as headaches, facial flushing, nasal congestion, and dyspepsia. These effects are, however, transitory and disappear with the suspension of the drug. Moreover, both sildenafil and vardenafil can act on PDE6, which is present in the retina, thus high doses can cause vision problems. Tadalafil, moreover, can inhibit PDE11. These drugs are not suitable for cardiopathic subjects, due to the possible vasodilatatory effects, and hypotensives, as well as in subjects who suffer from orthostatic hypotension, aortic stenosis, obstructive hypertrophic cardiomyopathy, and retinitis pigmentosa (Kulkarni and Patil 2004).

\section{PDE5 inhibitors and neurogenesis}

Neurogenesis is the production of new neurons, and it is a process that is active mostly during prenatal development, though new neurons are also produced during adult life in some areas of the brain such as the subventricular zone (SVZ) and the subgranular zone (SGZ) of the dentate gyrus of the hippocampus of mammals, including humans, and other species (Altman and Das 1965; Eriksson et al 1998; Gould et al 1999; Zhao et al 2003; Taupin 2006; Kim and Szele 2007). The functional significance of adult neurogenesis is just beginning to be understood and there is considerable disagreement in literature. There is evidence showing that adult neurogenesis in the hippocampus plays a role in synaptic plasticity (Sandeman and Sandeman 2000; Bruel-Jungerman et al 2006, 2007; Schmidt-Hieber et al 2004) and memory (Shors et al 2001, 2002; Snyder et al 2005; Bischofberger 2007; Bruel-Jungerman et al 2007; Dupret et al 2007; Epp et al 2007; Van der Borght et al 2007). Higher levels of neurogenesis resulting from an enriched environment are reported to correspond to better acquisition of the Morris Water Maze task in mice (Kempermann et al 2002) and new neurons have been shown to be necessary for consolidation of memory after water maze training (Snyder et al 2005). It seems that new neurons can increase mnemonic capacity (Becker 2005), reducing the interference between newly formed memories (Wiskott et al 2006), and adding spatial-temporal details to the new memory (Aimone et al 2006).

It also appears that neurogenesis plays a key role in the regulation of stress and that this is in turn linked to the integrity of the hippocampus. Some studies have, in fact, demonstrated that the positive activity of some antidepressants is linked to the stimulation of hippocampal 
neurogenesis (Malberg et al 2000; Manev et al 2001) and that inhibition of hippocampal neurogenesis induced by radiation blocks the effects of anti-depressants (Santarelli et al 2003). Other studies have shown that memory is correlated with mood disorders, particularly with depression, and that mood is regulated by the phenomena of neurogenesis and synaptic plasticity (Castren et al 2005; Paizanis et al 2007).

Hippocampal neurogenesis is controlled by various factors such as physical exercise, stress, sleep, environmental conditions, hormones (testosterone), neurotransmitters (serotonin) and intrinsic growth factors (Cameron and Gould 1994; Lledo et al 2006), which can affect different stages of the neurogenetic process. Neurogenesis is also stimulated by hippocampal or cortical damage (Covolan et al 2000; Blumcke et al 2001; Jiang et al 2001; Jin et al 2001) and could be modified by pathologies such as Alzheimer's disease (Kuhn et al 2007).

It is interesting to note that some studies have shown that sildenafil plays a role in potentiating neurogenesis through the increase of cGMP levels. NO influenced sensory-induced neurogenesis (Cayre et al 2005) and prenatal development of the brain through cGMP (Chen et al 2004). Furthermore, neuronal growth decreases with age in parallel with the reduction of cGMP levels (Taddei et al 2001). Several studies have demonstrated that sildenafil can be used to stimulate neurogenesis after stroke. In rats, Sildenafil induces neurogenesis, reduces neurological deficit and promotes the functional recovery after stroke and focal cerebral ischemia (Zhang et al 2002; 2006b). Tadalafil has also been used to improve neurogenesis in an embolic model of stroke in rats (Zhang et al 2006a). Thus, it is possible that in the future PDE5 inhibitors might be used to stimulate neuronal function and improve neurogenesis in older subjects or in patients affected by $\mathrm{AD}$ and other disorders characterized by hippocampal memory impairment.

\section{PDE5 inhibitors and memory}

Role of NO/cGMP in synaptic plasticity and memory Synaptic plasticity is an active phenomenon consisting of all the structural and/or neuronal functional modifications that allow adaptation to new situations (Hebb 1949). It is thought to be at the bases of learning and memory and occurs in various cerebral structures such as the hippocampus, the cerebral cortex and the cerebellum.

The most studied form of synaptic plasticity is long-term potentiation (LTP) occurring at the excitatory synapses of the hippocampus and consisting of an increase in the amplitude of the post-synaptic excitatory potentials
(EPSPs) after high frequency stimulation (tetanus) of the afferent fibers. LTP can be detected in various areas of the hippocampus but it is mostly observed in the CA1 pyramidal cells and pre-synaptic fibers forming the Schaffer collateral, which is implicated in learning and memory. Many studies support the hypothesis that LTP underlies memory (Larson et al 1986; Morris et al 1986; Rose and Dunwiddie 1986; Diamond et al 1988; Greenstein et al 1988; Buchs and Muller 1996; Lynch 2004), although the complex mechanisms involved in memory have not yet been fully clarified. Various studies have shown that LTP and memory depend on a cellular cascade stimulated by an increase of the intracellular concentrations of cAMP with the subsequent activation of PKA and the phosphorylation of the cAMP responsive element binding protein (CREB) (Bourtchuladze et al 1994; Huang and Kandel 1994; Yin et al 1994; Robertson and Sweatt 1996; Abel et al 1997; Montminy 1997; Murphy and Segal 1997; Shieh et al 1998; Tao et al 1998; Otmakhova et al 2002; Stanciu et al 2001; Gooney et al 2002). Besides cAMP, a fundamental role is played by the cGMP/PKG/CREB pathway that seems to act in parallel with the $\mathrm{cAMP} / \mathrm{PKA} / \mathrm{CREB}$ pathway.

Studying the role of the cGMP pathway in memory stems from the crucial need to identify pre- and post-synaptic mechanisms in LTP. In the early 1990s it was suggested that the induction of LTP involves a retrograde message released at the post-synaptic level and acting at the pre-synaptic level (Bohme et al 1991; O’Dell et al 1991; Schuman and Madison 1991). Various studies have shown that NO is necessary for LTP: i) inhibitors of NOS block LTP and this inhibition is corrected administering precursors of NO (Schuman and Madison 1991; Gribkoff and Lum-Ragan 1992; Haley et al 1992; Bohme et al 1991, 1993; Bon et al 1992); ii) knock-out mice for nNOS and eNOS show LTP impairment (Son et al 1996); iii) exogenous application of NO induces plasticity (Zhuo et al 1993; Arancio et al 1996; Bon and Garthwaite 2001); and iv) NO is able to stimulate the release of spontaneous pre-synaptic neurotransmitter release in cell cultures (O’Dell et al 1991).

Given that cGMP is a downstream effector of NO, the involvement of the cGMP/PKG/CREB pathway has also been investigated. These studies showed that: i) inhibitors of GC block the induction of LTP (Haley et al 1992; Zhuo et al 1994; Andreasen et al 2003); ii) analogs of cGMP produce potentiation despite the block of upstream NMDA receptors and NO release (Haley et al 1992; Arancio et al 1995); and iii) inhibitors of GC and of PKG block LTP (Arancio et al 1995, 2001). 
Behavioral studies have also shown that NO is involved in the phenomenon of learning and memory (Hawkins 1996; Susswein et al 2004). Bohme and colleagues (1991) demonstrated that the inhibition of endogenous NO impaired spatial learning tested with a radial arm maze and olfactive memory, but had no effect on shock-avoidance learning. Studies on nNOS knockout mice or by using inhibitors of NOS have shown an impairment of spatial performance with the Morris water maze (MWM) and object recognition memory in rats (Chapman et al 1992; Prickaerts et al 1997; Zou et al 1998; Kirchner et al 2004; Koylu et al 2005). Moreover, the block of spatial memory obtained by blocking the NMDA receptors could be restored using NO donors or cGMP analogs (Yamada et al 1996). The effect of NO on behavior is mediated by the cGMP/PKG pathway. In fact, passive avoidance learning in rats increased cGMP levels in the hippocampus and the administration of 8-Br-cGMP, a cGMP analog (Bernabeu et al 1996), or zaprinast, a selective cGMP PDE inhibitor (Prickaerts et al 1997), improved memory. On the other hand, the post-training inhibition of GC or PKG activity blocked memory formation (Bernabeu et al 1996).

\section{Role of NO/cGMP in Alzheimer's disease}

One of the most widespread and invalidating pathologies that causes a deficit of cognitive functions is Alzheimer's disease $(\mathrm{AD})$. $\mathrm{AD}$ is a progressive neurodegenerative disorder characterized by loss of memory and behavioral problems leading to dementia. The advanced stages of the pathology are characterized by the presence of senile plaques at the cerebral level, principally made up of beta-amyloid peptide $(A \beta)$ and neurofibrillary tangles (Selkoe 1994). However, the early symptoms, which consist in the loss of memory, also occur without signs of cerebral alterations and are probably due to a synaptic dysfunction caused by A $\beta$ (Cullen et al 1997; Lambert et al 1998; Itoh et al 1999; Chen et al 2000; Vitolo et al 2002; Walsh et al 2002). It appears, in fact, that $A \beta$ causes a deficit at the excitatory neurotransmission level causing a synaptic dysfunction that precedes the structural alteration with a loss of neurons (Selkoe 2002).

$\mathrm{A} \beta$ has various targets that have been well studied and that could identify new therapeutic approaches (Mattson 1997). Various studies suggest that the NO/cGMP pathway can be involved in the pathogenesis of AD. These studies have indicated a dual role for NO: neuroprotective and neurotoxic. Some authors have shown that by acting on the NO/cGMP pathway with NO donors, cGMP analogs, or PDE inhibitors, it is possible to obtain an improvement of the $A \beta$-induced damage both at the level of the CNS and the vascular system
(McCarty 1998; Mattson et al 1999; Paris et al 1999; Troy et al 2000; Wirtz-Brugger and Giovanni 2000). In particular, inhibition of PDEs appears to block the vasoconstriction and inflammation of the microglia induced by $\mathrm{A} \beta$ (Paris et al 2000). Given that the NO/cGMP/PKG pathway is involved in LTP, a phenomenon that is altered in the early phases of the pathology in transgenic mouse models (Trinchese et al 2004), it has been demonstrated that this pathway has a protective role with regards to A $\beta$-induced LTP impairment (Puzzo et al 2005). Moreover, an enhancement of this pathway has been associated with a restoration of the phosphorylation of CREB (Puzzo et al 2005), a transcription factor linked to memory (Bourtchuladze et al 1994; Yin et al 1994; Lonze and Ginty 2002). The potential neurotoxic role of NO has been focused on in many studies showing that activation of iNOS in microglia in response to $A \beta$ is involved in $A D$ pathogenesis (Parks et al 2001; Tran et al 2001; Haas et al 2002; Xie et al 2002). A unifying hypothesis that combines studies on protective and toxic roles of $\mathrm{NO}$ is that the two constitutive NOS, n-NOS and e-NOS, have a potential neuroprotective role while i-NOS mediates the oxidative stress induced by NO.

\section{Use of PDE5 inhibitors as a memory enhancer}

It has been shown that the PDE5 inhibitor sildenafil influences long-term memory retention in mice by modulating mechanisms involved in memory storage (Baratti and Boccia 1999). Moreover, the inhibition of PDE5 improves object memory (Prickaerts et al 2002, 2004; Rutten et al 2005) and counteracts spatial learning impairment induced by NOS inhibition (Devan et al 2005, 2006) and by blockade of cholinergic muscarinic receptors in rats (Devan et al 2005). Other studies have shown that sildenafil produces a dose-dependent improvement of memory in mice tested with elevated plus maze (Singh and Parle 2003). Sildenafil effects have also been tested on selective auditory attention and verbal recognition memory in humans (Schultheiss et al 2001). Despite the fact that no differences in behavioural patterns were found, sildenafil enhanced the ability to focus attention on streams of auditory stimuli, as revealed by an improvement of the typical ERP components.

As mentioned above, $A \beta$ has been implicated as a key molecule in AD pathogenesis. Several studies have tried to clarify the second messenger pathway(s) by which $A \beta$ affects synaptic plasticity and memory. The cAMP/PKA/CREB pathway has been found to be involved in A $\beta$-induced LTP impairment (Vitolo et al 2002; Gong et al 2004). Rolipram, a PDE4 inhibitor increasing cAMP levels, reversed the 
inhibition of PKA activity and CREB phosphorylation most probably by favoring the dissociation of regulatory and catalytic subunits of PKA and the restoration of PKA activity (Vitolo et al 2002). Moreover, treatment with Rolipram re-estabilished LTP and contextual learning in animal models of AD (APP/PS1 mice) and, most importantly, this beneficial effect could be extended beyond the duration of the administration (Gong et al 2004). A $\beta$ has also been found to downregulate the NO pathway leading to a reduction in CREB phosphorylation through reduced activation of PKG (Puzzo et al 2005). Recent studies have shown that nitrates might counteract microglia activation and $A \beta$ deposits (Troy et al 2000; Jantzen et al 2002) and NO-mimetic molecules may reverse cognitive impairment in $\mathrm{AD}$ (Thatcher et al 2002, 2005). Thus, enhancers of the cAMP/PKA/CREB or NO/cGMP/PKG/CREB pathways might represent novel classes of compounds that could effectively counteract disease progression by acting at the downstream level of $\mathrm{A} \beta$ production. PDE inhibitors have been proposed to be employed as memory enhancers (Blokland et al 2006; Rose et al 2005; Rutten et al 2007). With regard to the use of these inhibitors, it is noteworthy that the development of PDE4 inhibitors as CNS drugs has been a very difficult endeavour because of undesirable side effects, or lack of efficacy at the doses used to avoid side effects. For instance, the PDE4 inhibitor Rolipram, used for its anti-depressant and anti-inflammatory effects, causes a number of side-effects (especially nausea and headache), which have limited its therapeutic use (Souness et al 2000). Thus, it is possible that inhibiting PDE5s might be an alternative and perhaps more suitable strategy than inhibiting PDE4s to develop a drug targeted to CNS and memory.

Based on these findings, and considering that the current therapy for AD (acetylcholinesterase inhibitors, NMDA antagonists, drugs that reduce $A \beta$ levels or its oligomerization, formation of neurofibrils, oxidative stress, and inflammation of the microglia; Schenk et al 1999; Nakagami et al 2002; Walsh et al 2005) has a limited efficacy, our group is currently studying the possibility of using PDE5 inhibitors in AD. Acting on a specific A $\beta$ target such as the NO/cGMP/ PKG pathway through PDE5 inhibitors could represent a useful therapeutic approach to block the disease at an early stage, before structural damage occurs. Moreover, it appears that $A \beta$, other than accumulating in the brain, is also present in the blood stream where it can cause phenomena of vasoconstriction that lead to arterial hypertension (Basun et al 2002; Andreasen et al 2003; Kalaria 2003; Suhara et al 2003; Price et al 2004; Smith et al 2004), often associated with AD (Pasquier and Leys 1998; Gentile et al 2004; Price et al 2004). It would thus be interesting to use PDE5 inhibitors to contrast both the neurological and vascular symptoms associated with this pathology.

\section{Use of PDE5 inhibitors in other nervous system diseases}

All PDEs are expressed at the level of the nervous system suggesting that they could be targeted by some drugs used for pathologies of the nervous system. Sildenafil has been proposed for pain therapy both in humans and animals (Asomoza-Espinosa et al 2001; Jain et al 2001; Patil et al 2004; Ambriz-Tututi et al 2005). Chronic neuropathic pain, often associated with nervous system diseases, is very difficult to treat therapeutically (Pezet and McMahon 2006). Opioids have been found ineffective and the possible use of a low dose of ketamine produces a transient amelioration (Eide et al 1995; Mathisen et al 1995; Wiesenfeld-Hallin 1998; Pedersen et al 2006), but can also give memory impairment and psychotic symptoms (Krystal et al 1994; Malhotra et al 1996). Recent studies have shown that sildenafil can be used for the treatment of pain in animal models (AsomozaEspinosa et al 2001; Jain et al 2001; Patil et al 2004; AmbrizTututi et al 2005) because of the peripheral accumulation of cGMP that it is likely to have an anti-nociceptive effect (Jain et al 2003). A further interesting application would be the treatment of diabetic neuropathy in which alteration in nNOS seems to be a key factor (Patil et al 2004).

Sildenafil has also been shown to have a potential application in MS, a chronic inflammatory CNS disease characterized by demyelinization of nerve cells that leads to severe psychomotor disability. There is no definitive therapy for MS but the different approaches (interferon, glatiramer acetate, novantrone, natalizumab, corticosteroids, and miorelaxants) aim to cure the symptoms and the progression of the pathology. Given its role in neuroprotection and neurogenesis (see above), sildenafil might have a potential application in patients with MS. Moreover, it has been demonstrated that sildenafil can be useful to successfully treat ED in MS (Fowler et al 2005) and other neurological disorders such as spina bifida and Parkinson's disease (Nehra and Moreland 2001).

\section{Conclusions}

This review summarizes the effect of PDE5 in physiological processes and, in particular, on synaptic plasticity and memory. Given the widespread distribution of PDE5, the use of selective PDE5 inhibitors such as sildenafil, vardenafil, and tadalafil has been widely investigated. The use of PDE5 
inhibitors is now approved by the FDA for the therapy of ED and pulmonary hypertension, however, many other diseases might take advantage of these drugs. Among these, particular attention should be given to CNS diseases characterized by cognitive impairment such as AD. Moreover, given the role of sildenafil in neurogenesis, CNS diseases such as mood disorders, MS and stroke might be approached with PDE5 inhibitors. The role of PDE5 on nociception should be another field of further investigation.

\section{Acknowledgments}

This work was supported by NIH-NINDS grant \#NS049442 to Ottavio Arancio and the Alzheimer's Association grant \# NIRG-07-59597 to Daniela Puzzo. The authors report no conflicts of interest.

\section{References}

Abel T, Nguyen PV, Barad M, et al. 1997. Genetic demonstration of a role for PKA in the late phase of LTP and hippocampus-based long-term memory. Cell, 88:615-26.

Aimone JB, Wiles J, Gage FH. 2006. Potential role for adult neurogenesis in the encoding of time in new memories. Nat Neurosci, 9:723-7.

Altman J, Das GD. 1965. Autoradiographic and histological evidence of postnatal hippocampal neurogenesis in rats. J Comp Neurol, 124:319-35.

Ambriz-Tututi M, Velázquez-Zamora DA, Urquiza-Marín H, et al. 2005. Analysis of the mechanism underlying the peripheral antinociceptive action of sildenafil in the formalin test. Eur $J$ Pharmacol, 512(2-3):121-7.

Andreasen N, Sjogren M, Blennow K. 2003. CSF markers for Alzheimer's disease: total tau, phospho-tau and Abeta42. World J Biol Psychiatry, $4: 147-55$.

Andreeva SG, Dikkes P, Epstein PM, et al. 2001. Expression of cGMPspecific phosphodiesterase 9A mRNA in the rat brain. $J$ Neurosci, 21:9068-76.

Arancio O, Antonova I, Gambaryan S, et al. 2001. Presynaptic cGMPdependent protein kinase contributes to long-lasting potentiation in cultured hippocampal neurons. J Neurosci, 21:143-9.

Arancio O, Kandel ER, Hawkins RD. 1995. Activity-dependent long-term enhancement of transmitter release by presynaptic 3', 5' -cyclic GMP in cultured hippocampal neurons. Nature, 376:74-80.

Arancio O, Kiebler M, Lee CJ, et al. 1996. Nitric oxide acts directly in the presynaptic neuron to produce long-term potentiation in cultured hippocampal neurons. Cell, 87:1025-35.

Ariano MA, Appleman MM. 1979. Biochemical characterization of postsynaptically localized cyclic nucleotide phosphodiesterase. Brain Res, 177:301-9.

Ashman DF, Lipton R, Melicow MM, et al. 1963. Isolation of adenosine 3',5'-monophosphate and guanosine 3',5'-monophosphate from rat urine. Biochem Biophys Res Commun, 11:330-4.

Asomoza-Espinosa R, Alonso-Lopez R, Mixcoatl-Zecuatl T, et al. 2001. Sildenafil increases diclofenac antinociception in the formalin test. Eur J Pharmacol, 418:195-200.

Barad M, Bourtchouladze R, Winder DG, et al. 1998. Rolipram, a type IV-specific phosphodiesterase inhibitor, facilitates the establishment of long-lasting long-term potentiation and improves memory. Proc Natl Acad Sci USA, 95:15020-5.

Baratti CM, Boccia MM. 1999. Effects of sildenafil on long-term retention of an inhibitory avoidance response in mice. Behav Pharmacol, 10:731-7.

Barnstable CJ, Wei JY, Han MH. 2004. Modulation of synaptic function by cGMP and cGMP-gated cation channels. Neurochem Int, 45:875-84.
Basun H, Nilsberth C, Eckman C, et al. 2002. Plasma levels of Abeta42 and Abeta40 in Alzheimer patients during treatment with the acetylcholinesterase inhibitor tacrine. Dement Geriatr Cogn Disord, 14:156-60.

Beavo JA, Conti M, Heaslip RJ. 1994. Multiple cyclic nucleotide phosphodiesterases. Mol Pharmacol, 46:399-405.

Beavo JA, Hardman JG, Sutherland EW. 1970. Hydrolysis of cyclic guanosine and adenosine 3',5'-monophosphates by rat and bovine tissues. J Biol Chem, 245:5649-55.

Beavo JA. 1995. Cyclic nucleotide phosphodiesterases: functional implications of multiple isoforms. Physiol Rev, 75:725-48.

Becker S. 2005. A computational principle for hippocampal learning and neurogenesis. Hippocampus, 15:722-38.

Bender AT, Beavo JA. 2006. Cyclic nucleotide phosphodiesterases: molecular regulation to clinical use. Pharmacol Rev, 58:488-520.

Bernabeu R, Schmitz P, Faillace MP, et al. 1996. Hippocampal cGMP and cAMP are differentially involved in memory processing of inhibitory avoidance learning. Neuroreport, 7:585-8.

Berthet J, Sutherland EW, Rall TW. 1957. The assay of glucagon and epinephrine with use of liver homogenates. J Biol Chem, 229:351-61.

Bischofberger J. 2007. Young and excitable: new neurons in memory networks. Nat Neurosci, 10:273-5.

Blokland A, Schreiber R, Prickaerts J. 2006. Improving memory: A role for phosphodiesterases. Curr Pharm Des, 12:2511-23.

Boess FG, Hendrix M, van der Staay FJ, et al. 2004. Inhibition of phosphodiesterase 2 increases neuronal cGMP, synaptic plasticity and memory performance. Neuropharmacology, 47:1081-92.

Bohme GA, Bon C, Lemaire M, et al. 1993. Altered synaptic plasticity and memory formation in nitric oxide synthase inhibitor-treated rats. Proc Natl Acad Sci USA, 90:9191-4.

Bohme GA, Bon C, Stutzmann J-M, et al. 1991. Possible involvement of nitric oxide in long-term potentiation. Eur J Pharmacol, 199:379-81.

Bon C, Bohme GA, Doble A, et al. 1992. A role for nitric oxide in long-term potentiation. Eur J Neurosci, 4:420-4.

Bon CL, Garthwaite J. 2001. Exogenous nitric oxide causes potentiation of hippocampal synaptic transmission during low-frequency stimulation via the endogenous nitric oxide-cGMP pathway. Eur J Neurosci, 14:585-94.

Bon CL, Garthwaite J. 2003. On the role of nitric oxide in hippocampal long-term potentiation. $J$ Neurosci, 23:1941-8.

Boswell-Smith V, Spina D, Page CP. 2006. Phosphodiesterase inhibitors. Br J Pharmacol, 147(Suppl 1):S252-7.

Bourtchuladze R, Frenguelli B, Blendy J, et al. 1994. Deficient long-term memory in mice with a targeted mutation of the cAMP-responsive element-binding protein. Cell, 79:59-68.

Bruel-Jungerman E, Davis S, Rampon C, et al. 2006. Long-term potentiation enhances neurogenesis in the adult dentate gyrus. $J$ Neurosci, 26:5888-93.

Bruel-Jungerman E, Rampon C, Laroche S. 2007. Adult hippocampal neurogenesis, synaptic plasticity and memory: facts and hypotheses. Rev Neurosci, 18:93-114.

Brunton L. 1867. On the use of nitrite of amyl in angina pectoris. Lancet, ii:97-8.

Buchs PA, Muller D. 1996. Induction of long-term potentiation is associated with major ultrastructural changes of activated synapses. Proc Natl Acad Sci USA, 93:8040-5.

Bumcke I, Schewe JC, Normann S, et al. 2001. Increase of nestinimmunoreactive neural precursor cells in the dentate gyrus of pediatric patients with early-onset temporal lobe epilepsy. Hippocampus, 11:311-21.

Burgers PM, Eckstein F, Hunneman DH, et al. 1979. Stereochemistry of hydrolysis of adenosine 3':5'-cyclic phosphorothioate by the cyclic phosphodiesterase from beef heart. J Biol Chem, 254:9959-61.

Butcher RW, Sutherland EW. 1962. Adenosine 3',5'-phosphate in biological materials. I. Purification and properties of cyclic 3',5'-nucleotide phosphodiesterase and use of this enzyme to characterize adenosine 3',5'-phosphate in human urine. J Biol Chem, 237:1244-50. 
Callahan SM, Cornell NW, Dunlap PV. 1995. Purification and properties of periplasmic 3':5'-cyclic nucleotide phosphodiesterase: a novel zinccontaining enzyme from the marine symbiotic bacterium Vibrio fischeri. J Biol Chem, 270:17627-32.

Cameron HA, Gould E. 1994. Adult neurogenesis is regulated by adrenal steroids in the dentate gyrus. Neuroscience, 61:203-9.

Castrén E. 2005. Is mood chemistry? Nat Rev Neurosci, 6:241-6.

Cawley SM, Sawyer CL, Brunelle KF, et al. 2007. Nitric oxide-evoked transient kinetics of cyclic GMP in vascular smooth muscle cells. Cell Signal, 19:1023-33.

Cayre M, Malaterre J, Scotto-Lomassese S, et al. 2005. A role for nitric oxide in sensory-induced neurogenesis in an adult insect brain. Eur $J$ Neurosci, 21:2893-902.

Chapman PF, Atkins CM, Allen MT, et al. 1992. Inhibition of nitric oxide synthesis impairs two different forms of learning. Neuroreport, 3:567-70.

Chen CN, Denome S, Davis RL. 1986. Molecular analysis of cDNA clones and the corresponding genomic coding sequences of the Drosophila dunce+ gene, the structural gene for cAMP phosphodiesterase. Proc Natl Acad Sci USA, 83:9313-17.

Chen J, Tu Y, Moon C, et al. 2004. The localization of neuronal nitric oxide synthase may influence its role in neuronal precursor proliferation and synaptic maintenance. Dev Biol, 269:165-82.

Chen QS, Kagan BL, Hirakura Y, et al. 2000. Impairment of hippocampal long-term potentiation by Alzheimer amyloid beta-peptides. J Neurosci Res, 60:65-72.

Cherry JA, Davis RL. 1999. Cyclic AMP phosphodiesterases are localized in regions of the mouse brain associated with reinforcement, movement, and affect. J Comp Neurol, 407:287-301.

Cho CH, Cho DH, Seo MR, et al. 2000. Differential changes in the expression of cyclic nucleotide phosphodiesterase isoforms in rat brains by chronic treatment with electroconvulsive shock. Exp Mol Med, 32:110-14.

Cohen AH, Hanson K, Morris K, et al. 1996. Inhibition of cyclic 3'-5'guanosine monophosphate-specific phosphodiesterase selectively vasodilates the pulmonary circulation in chronically hypoxic rats. J Clin Invest, 97:172-9.

Corbin JD, Francis SH. 1999. Cyclic GMP phosphodiesterase-5: target of sildenafil. J Biol Chem, 274:13729-32.

Corbin JD, Turko IV, Beasley A, et al. 2000. Phosphorylation of phosphodiesterase- 5 by cyclic nucleotide-dependent protein kinase alters its catalytic and allosteric cGMP-binding activities. Eur J Biochem, 267:2760-7.

Covolan L, Ribeiro LT, Longo BM, et al. 2000. Cell damage and neurogenesis in the dentate granule cell layer of adult rats after pilocarpine- or kainate-induced status epilepticus. Hippocampus, 10:169-80.

Cullen WK, Suh YH, Anwyl R, et al. 1997. Block of LTP in rat hippocampus in vivo by beta-amyloid precursor protein fragments. Neuroreport, $8: 3213-17$.

Daugan A, Grondin P, Ruault C, et al. 2003. The discovery of tadalafil: a novel and highly selective PDE5 inhibitor. 2: 2,3,6,7,12,12ahexahydropyrazino[1',2':1,6] pyrido[3,4-b]indole-1,4-dione analogues. J Med Chem, 46:4533-42.

Devan BD, Bowker JL, Duffy KB, et al. 2006. Phosphodiesterase inhibition by sildenafil citrate attenuates a maze learning impairment in rats induced by nitric oxide synthase inhibition. Psychopharmacology (Berl), 183:439-45.

Devan BD, Duffy KB, Bowker JL, et al. 2005. Phosphodiesterase type 5 (PDE5) inhibition and cognitive enhancement. Drugs of the Future, 30:725-36.

DeVoti J, Seydoux G, Beach D, et al. 1991. Interaction between ran1+ protein kinase and cAMP dependent protein kinase as negative regulators of fission yeast meiosis. Embo J, 10:3759-68.

Diamond DM, Dunwiddie TV, Rose GM. 1988. Characteristics of hippocampal primed burst potentiation in vitro and in the awake rat. J Neurosci, 8:4079-88.

Dismukes RK, Daly JW. 1976. Adaptive responses of brain cyclic AMPgenerating systems to alterations in synaptic input. J Cyclic Nucleotide Res, 2:321-36.
Dixon D, Atwood HL. 1989. Adenylate cyclase system is essential for long-term facilitation at the crayfish neuromuscular junction. JNeurosci, 9:4246-52.

Dolci S, Belmonte A, Santone R, et al. 2006. Subcellular localization and regulation of type-1C and type-5 phosphodiesterases. Biochem Biophys Res Commun, 341:837-46.

D'Sa C, Tolbert LM, Conti M, et al. 2002. Regulation of cAMP-specific phosphodiesterases type 4B and 4D (PDE4) splice variants by cAMP signaling in primary cortical neurons. J Neurochem, 81:745-57.

Dunlap PV, Callahan SM. 1993. Characterization of a periplasmic 3':5'cyclic nucleotide phosphodiesterase gene, cpdP, from the marine symbiotic bacterium Vibrio fischeri. J Bacteriol, 175:4615-24.

Dupret D, Fabre A, Dobrossy MD, et al. 2007. Spatial learning depends on both the addition and removal of new hippocampal neurons. PLoS Biol, 5:e214.

Eide K, Stubhaug A, Oye I, et al. 1995. Continuous subcutaneous administration of the N-methyl-D-aspartic acid (NMDA) receptor antagonist ketamine in the treatment of post-herpetic neuralgia. Pain, 61:221-8.

Epp JR, Spritzer MD, Galea LA. 2007. Hippocampus-dependent learning promotes survival of new neurons in the dentate gyrus at a specific time during cell maturation. Neuroscience, 149:273-85.

Epplen JT, Kaltenhauser H, Engel W, et al. 1982. Patterns of cyclic AMP phosphodiesterases in the rat pineal gland: sex differences in diurnal rhythmicity. Neuroendocrinology, 34:46-54.

Eriksson PS, Perfilieva E, Bjork-Eriksson T, et al. 1998. Neurogenesis in the adult human hippocampus. Nat Med, 4:1313-7.

Esteban JA, Shi SH, Wilson C, et al. 2003. PKA phosphorylation of AMPA receptor subunits controls synaptic trafficking underlying plasticity. Nat Neurosci, 6:136-43.

Exton JH, Robison GA, Sutherland EW. 1971. Studies on the role of adenosine 3',5'-monophosphate in the hepatic actions of glucagon and catecholamines. J Biol Chem, 246:6166-77.

[FDA] Food and Drug Administration. Viagra tablets (sildenafil citrate). 1998. Review and evaluation of pharmacology and toxicology data. Report from the Division of Cardio-renal Drug Products (HFD-10). Center for Drug Evaluation and Research. in Food and Drug Administration 121-122 (Washington, DC).

Feil R, Hofmann F, Kleppisch T. 2005. Function of cGMP-dependent protein kinases in the nervous system. Rev Neurosci, 16:23-41.

Fisher DA, Smith JF, Pillar JS, et al. 1998. Isolation and characterization of PDE9A, a novel human cGMP-specific phosphodiesterase. J Biol Chem, 273:15559-64.

Forgue ST, Patterson BE, Bedding AW, et al. 2006. Tadalafil pharmacokinetics in healthy subjects. Br J Clin Pharmaco, 61:280-8.

Fowler CJ, Miller JR, Sharief MK, et al. 2005. A double blind, randomised study of sildenafil citrate for erectile dysfunction in men with multiple sclerosis. J Neurol Neurosurg Psychiatry, 76:700-5.

Francis SH, Bessay EP, Kotera J, et al. 2002. Phosphorylation of isolated human phosphodiesterase-5 regulatory domain induces an apparent conformational change and increases cGMP binding affinity. $J$ Biol Chem, 277:47581-7.

Francis SH, Colbran JL, McAllister-Lucas LM, et al. 1994. Zinc interactions and conserved motifs of the cGMP-binding cGMP-specific phosphodiesterase suggest that it is a zinc hydrolase. $J$ Biol Chem, 269:22477-80.

Francis SH, Corbin JD. 1988. Purification of cGMP-binding protein phosphodiesterase from rat lung. Methods Enzymol, 159:722-9.

Francis SH, Corbin JD. 1999. Cyclic nucleotide-dependent protein kinases: intracellular receptors for cAMP and cGMP action. Crit Rev Clin Lab Sci, 36:275-328.

Francis SH, Lincoln TM, Corbin JD. 1980. Characterization of a novel cGMP binding protein from rat lung. J Biol Chem, 255:620-6.

Francis SH, Turko IV, Corbin JD. 2000. Cyclic nucleotide phosphodiesterases: relating structure and function. Prog Nucleic Acid Res Mol Biol, 65:1-52.

Furchgott RF, Vanhoutte PM. 1989. Endothelium-derived relaxing and contracting factors. FASEB J, 3:2007-18. 
Garbers DL, Lowe DG. 1994. Guanylyl cyclase receptors. J Biol Chem, 269:30741-4.

Garthwaite J, Boulton CL. 1995. Nitric oxide signalling in the central nervous system. Annu Rev Physiol, 57:683-706.

Gentile MT, Vecchione C, Maffei A, et al. 2004. Mechanisms of soluble beta-amyloid impairment of endothelial function. $J$ Biol Chem, 279:48135-42.

Ghali-Ghoul R, Tahseldar-Roumieh R, Sabra R. 2007. Effect of chronic administration of sildenafil on sodium retention and on the hemodynamic complications associated with liver cirrhosis in the rat. Eur $J$ Pharmacol, 572:49-56.

Goldberg ND, Walseth TF, Stephenson JH, et al. 1980. 18O-Labeling of guanosine monophosphate upon hydrolysis of cyclic guanosine $3 ': 5$ 'monophosphate by phosphodiesterase. J Biol Chem, 255:10344-7.

Gong B, Vitolo OV, Trinchese F, et al. 2004. Persistent improvement in synaptic and cognitive functions in an Alzheimer mouse model after rolipram treatment. $J$ Clin Invest, 114:1624-34.

Gooney MA, Shaw K, Kelly A, et al. 2002. Long-term potentiation and spatial learning are associated with increased phosphorylation of TrkB and extracellular signal regulated kinase (ERK) in the dentate gyrus: evidence for a role for brain-derived neurotrophic factor. Behav Neurosci, 116:455-63.

Gould E, Reeves AJ, Graziano MS, et al. 1999. Neurogenesis in the neocortex of adult primates. Science, 286:548-52.

Greenstein YJ, Pavlides C, Winson J. 1988. Long-term potentiation in the dentate gyrus is preferentially induced at theta rhythm periodicity. Brain Res, 438:331-4.

Gribkoff VK, Lum-Ragan JT. 1992. Evidence for nitric oxide synthase inhibitor- sensitive and in sensitive hippocampal synaptic potentiation. J Neurophysiol, 68:639-42.

Haas J, Storch-Hagenlocher B, Biessmann A, et al. 2002. Inducible nitric oxide synthase and argininosuccinate synthetase: co-induction in brain tissue of patients with Alzheimer's dementia and following stimulation with beta-amyloid 1-42 in vitro. Neurosci Lett, 322:121-5.

Haley JE, Wilcox GL, Chapman PF. 1992. The role of nitric oxide in hippocampal long-term potentiation. Neuron, 8:211-16.

Hawkins RD. 1996. NO honey, I don't remember. Neuron, 16:465-7.

$\mathrm{He} F$, Seryshev AB, Cowan CW, et al. 2000. Multiple zinc binding sites in retinal rod cGMP phosphodiesterase, PDE6alpha beta. J Biol Chem, 275:20572-7.

Hebb DO. 1949. The organization of Behaviour: A neuropsychological theory. New York: Wiley.

Hofmann F, Dostmann W, Keilbach A, et al. 1992. Structure and physiological role of cGMP-dependent protein kinase. Biochim Biophys Acta, 1135:51-60.

Houslay MD, Adams DR. 2003. PDE4 cAMP phosphodiesterases: modular enzymes that orchestrate signalling cross-talk, desensitization and compartmentalization. Biochem J, 370:1-18.

Houslay MD. 2001. PDE4 cAMP-specific phosphodiesterases. Prog Nucleic Acid Res Mol Biol, 69:249-315.

Hoyer LL, Cieslinski LB, McLaughlin MM, et al. 1994. A Candida albicans cyclic nucleotide phosphodiesterase: cloning and expression in Saccharomyces cerevisiae and biochemical characterization of the recombinant enzyme. Microbiology, 140:1533-42.

Huang Y, Kandel ER. 1994. Recruitment of long-lasting and protein kinase A-dependent long-term potentiation in the CA1 region of hippocampus requires repeated tetanization. Learn Mem, 1:74-82.

Itoh A, Akaike T, Sokabe M, et al. 1999. Impairments of long-term potentiation in hippocampal slices of beta-amyloid-infused rats. Eur $J$ Pharmacol, 382:167-75.

Jackson G, Benjamin N, Jackson N, et al. 1999. Effects of sildenafil citrate on human hemodynamics. Am J Cardiol, 83:13C-20C.

Jain NK, Patil CS, Singh A, et al. 2001. Sildenafil induced peripheral analgesia and activation of the nitric oxide - cyclic GMP pathway. Brain Res, 909:170-8.

Jain NK, Patil CS, Singh A, et al. 2003. Sildenafil, a phosphodiesterase-5 inhibitor, enhances the antinociceptive effect of morphine. Pharmacology, 67:150-6.
Jantzen PT, Connor KE, DiCarlo G, et al. 2002. Microglial activation and beta-amyloid deposit reduction caused by a nitric oxide-releasing nonsteroidal anti-inflammatory drug in amyloid precursor protein plus presenilin-1 transgenic mice. J Neurosci, 22:2246-54.

Jiang W, Gu W, Brannstrom T, et al. 2001. Cortical neurogenesis in adult rats after transient middle cerebral artery occlusion. Stroke, 32:1201-7.

Jin K, Minami M, Lan JQ, et al. 2001. Neurogenesis in dentate subgranular zone and rostral subventricular zone after focal cerebral ischemia in the rat. Proc Natl Acad Sci USA, 98:4710-15.

Jin SL, Swinnen JV, Conti M. 1992. Characterization of the structure of a low $\mathrm{Km}$, rolipram-sensitive cAMP phosphodiesterase. Mapping of the catalytic domain. $J$ Biol Chem, 267:18929-39.

Kalaria RN. 2003. Vascular factors in Alzheimer's disease. Int Psychogeriatr, 15(Suppl 1):47-52.

Kandel ER, Schwartz JH. 1982. Molecular biology of learning: modulation of transmitter release. Science, 218:433-43.

Kariya T, Dage RC. 1988. Tissue distribution and selective inhibition of subtypes of high affinity cAMP phosphodiesterase. Biochem Pharmacol, 37:3267-70.

Kempermann G, Gast D, Gage FH. Neuroplasticity in old age: sustained fivefold induction of hippocampal neurogenesis by long-term environmental enrichment. Ann Neurol, 52:135-43.

Kim Y, Szele FG. 2007. Activation of subventricular zone stem cells after neuronal injury. Cell Tissue Res, 331:337-45.

Kirchner L, Weitzdoerfer R, Hoeger H, et al. 2004. Impaired cognitive performance in neuronal nitric oxide synthase knockout mice is associated with hippocampal protein derangements. Nitric oxide, 11:316-30.

Kobayashi T, Gamanuma M, Sasaki T, et al. 2003. Molecular comparison of rat cyclic nucleotide phosphodiesterase 8 family: unique expression of PDE8B in rat brain. Gene, 319:21-31.

Kotera J, Fujishige K, Omori K. 2000. Immunohistochemical localization of cGMP-binding cGMP-specific phosphodiesterase (PDE5) in rat tissues. $J$ Histochem Cytochem, 48:685-93.

Koyanagi M, Suga H, Hoshiyama D, et al. 1998. Ancient gene duplication and domain shuffling in the animal cyclic nucleotide phosphodiesterase family. FEBS Lett 1998; 436:323-28.

Koylu EO, Kanit L, Taskiran D, et al. 2005. Effects of nitric oxide synthase inhibition on spatial discrimination learning and central DA2 and $\mathrm{mACh}$ receptors. Pharmacol Biochem Behav, 81:32-40.

Krystal JH, Karper LP, Seibyl JP, et al. 1994. Subanesthetic effects of the noncompetitive NMDA antagonist, ketamine, in humans. Psychotomimetic, perceptual, cognitive and neuroendocrine responses. Arch Gen Psychiatry, 51:199-214.

Kuenzi F, Rosahl TW, Morton RA, et al. 2003. Hippocampal synaptic plasticity in mice carrying the rd mutation in the gene encoding cGMP phosphodiesterase type 6 (PDE6). Brain Res, 967:144-51.

Kuhn HG, Cooper-Kuhn CM, Boekhoorn K, et al. 2007. Changes in neurogenesis in dementia and Alzheimer mouse models: are they functionally relevant? Eur Arch Psychiatry Clin Neurosci, 257:281-9.

Kulkarni SK, Patil CS. 2004. Phosphodiesterase 5 enzyme and its inhibitors: update on pharmacological and therapeutical aspects. Methods Find Exp Clin Pharmacol, 26:789-99.

Lacombe ML, Podgorski GJ, Franke J, et al. 1986. Molecular cloning and developmental expression of the cyclic nucleotide phosphodiesterase gene of Dictyostelium discoideum. J Biol Chem, 261:16811-17.

Lal S, Raju RV, Macaulay RJ, et al. 1996. Calmodulin-dependent cyclic nucleotide phosphodiesterase in human cerebral cortex and glioblastoma multiforme. Can J Neurol Sci, 23:245-50.

Lambert MP, Barlow AK, Chromy BA, et al. 1998. Diffusible, nonfibrillar ligands derived from Abeta1-42 are potent central nervous system neurotoxins. Proc Natl Acad Sci USA, 95:6448-53.

Larrue B, Jaillard S, Lorthioir M, et al. 2005. Pulmonary vascular effects of sildenafil on the development of chronic pulmonary hypertension in the ovine fetus. Am J Physiol Lung Cell Mol Physiol, 288:L1193-200.

Larson J, Wong D, Lynch G. 1986. Patterned stimulation at the theta frequency is optimal for the induction of hippocampal long-term potentiation. Brain Res, 368:347-50. 
Lewis GD, Semigran MJ. 2004. Type 5 phosphodiesterase inhibition in heart failure and pulmonary hypertension. Curr Heart Fail Rep, 1:183-9.

Lin CS. 2004. Tissue expression, distribution, and regulation of PDE5. Int J Impot Res, 16(Suppl 1):S8-S10.

Lincoln TM, Cornwell TL. 1993. Intracellular cyclic GMP receptor proteins. FASEB J, 7:328-38.

Liu L, Underwood T, Li H, et al. 2002. Specific cGMP binding by the cGMP binding domains of cGMP-binding cGMP specific phosphodiesterase. Cell Signal, 14:45-51

Liu S, Fa M, Ninan I, et al. 2007. Alpha-synuclein involvement in hippocampal synaptic plasticity: role of NO, cGMP, cGK and CaMKII. Eur J Neurosci, 25:3583-96.

Lledo PM, Alonso M, Grubb MS. Adult neurogenesis and functional plasticity in neuronal circuits. Nat Rev Neurosci, 7:179-93.

Lobban M, Shakur Y, Beattie J, et al. 1994. Identification of two splice variant forms of type-IVB cyclic AMP phosphodiesterase, DPD (rPDE-IVB1) and PDE-4 (rPDE-IVB2) in brain: selective localization in membrane and cytosolic compartments and differential expression in various brain regions. Biochem J, 304:399-406.

Lohmann SM, Vaandrager AB, Smolenski A, et al. 1997. Distinct and specific functions of cGMP-dependent protein kinases. TIBS, 22:307-12.

Lonze BE, Ginty DD. 2002. Function and regulation of CREB family transcription factors in the nervous system. Neuron, 35:605-23.

Loughney K, Hill TR, Florio VA, et al. 1998. Isolation and characterization of cDNAs encoding PDE5A, a human cGMP-binding, cGMP-specific 3',5'-cyclic nucleotide phosphodiesterase. Gene, 216:139-47.

Lu YF, Kandel ER, Hawkins RD. 1999. Nitric oxide signaling contributes to late-phase LTP and CREB phosphorylation in the hippocampus. J Neurosci, 19:10250-61.

Lynch AM. 2004. Long-term potentiation and memory. Physiol Rev, 84:87-136.

Makhinson M, Opazo P, Carlisle HJ, et al. 2006. A novel role for cyclic guanosine 3',5'monophosphate signaling in synaptic plasticity: a selective suppressor of protein kinase A-dependent forms of long-term potentiation. Neuroscience, 140:415-31.

Malberg JE, Eisch AJ, Nestler EJ, et al. 2000. Chronic antidepressant treatment increases neurogenesis in adult rat hippocampus. $J$ Neurosci, 20:9104-10.

Malhotra AK, Pinals DA, Weingartner H, et al. 1996. NMDA receptor function and human cognition: the effects of ketamine in healthy volunteers. Neuropsychopharmacology, 14:301-7.

Manev H, Uz T, Smalheiser NR, et al. 2001. Antidepressants alter cell proliferation in the adult brain in vivo and in neural cultures in vitro. Eur J Pharmacol, 411:67-70.

Mathisen LC, Skjelbred P, Skoglund LA, et al. 1995. Effect of ketamine, an NMDA receptor inhibitor, in acute and chronic orofacial pain. Pain, 61:215-20.

Mattson MP, Guo ZH, Geiger JD. 1999. Secreted form of amyloid precursor protein enhances basal glucose and glutamate transport and protects against oxidative impairment of glucose and glutamate transport in synaptosomes by a cyclic GMP-mediated mechanism. J Neurochem, 73:532-7.

Mattson MP. 1997. Cellular actions of beta-amyloid precursor protein and its soluble and fibrillogenic derivatives. Physiol Rev, 77:1081-132.

McAllister-Lucas LM, Haik TL, Colbran JL, et al. 1995. An essential aspartic acid at each of two allosteric cGMP-binding sites of a cGMP-specific phosphodiesterase. J Biol Chem, 270:30671-9.

McAllister-Lucas LM, Sonnenburg WK, Kadlecek A, et al. 1993. The structure of a bovine lung cGMP-binding, cGMP-specific phosphodiesterase deduced from a cDNA clone. J Biol Chem, 268:22863-73.

McCarty MF. 1998. Vascular nitric oxide may lessen Alzheimer's risk. Med Hypotheses, 51:465-76.

Menniti FS, Faraci WS, Schmidt CJ. 2006. Phosphodiesterases in the CNS: targets for drug development. Nat Rev Drug Discov, 5:660-70.

Miró X, Pérez-Torres S, Palacios JM, et al. 2001. Differential distribution of cAMP-specific phosphodiesterase 7A mRNA in rat brain and peripheral organs. Synapse, 40:201-14.
Montminy M. 1997. Transcriptional regulation by cyclic AMP. Annu Rev Biochem, 66:807-22.

Moro MA, Russel RJ, Cellek S, et al. 1996. cGMP mediates the vascular and platelet actions of nitric oxide: confirmation using an inhibitor of the soluble guanylyl cyclase. Proc Natl Acad Sci USA, 93:1480-5.

Morris RG, Anderson E, Lynch GS et al. 1986. Selective impairment of learning and blockade of long-term potentiation by an N-methil-Daspartate receptor antagonist, AP5. Nature, 319:774-6.

Murphy DD, Segal M. 1997. Morphological plasticity of dentritic spines in central neurons is mediated by activation of cAMP response elements binding protein. Proc Natl Acad Sci USA, 94:1482-7.

Nakagami Y, Nishimura S, Murasugi T, et al. 2002. A novel beta-sheet breaker, RS-0406, reverses amyloid beta-induced cytotoxicity and impairment of long-term potentiation in vitro. $\mathrm{Br} J$ Pharmacol, 137:676-82.

Nehra A, Moreland RB. 2001. Neurologic erectile dysfunction. Urol Clin North Am, 28:289-308.

Nikawa J, Sass P, Wigler M. 1987. Cloning and characterization of the low-affinity cyclic AMP phosphodiesterase gene of Saccharomyces cerevisiae. Mol Cell Biol, 7:3629-36.

Noyama K, Maekawa S. 2003. Localization of cyclic nucleotide phosphodiesterase 2 in the brain-derived Triton-insoluble low-density fraction (raft). Neurosci Res, 45:141-8.

O'Dell TJ, Hawkins RD, Kandel E, et al. 1991. Tests of the roles of two diffusible substances in long-term potentiation: evidence for nitric oxide a possible early retrograde messenger. Proc Natl Acad Sci USA, 88:11285-89.

Otmakhova NA, Otmakhov N, Mortenson LH, et al. 2002. Inhibition of the cAMP pathway decreases early long-term potentiation at CA1 hippocampal synapses. J Neurosci, 20:4446-51.

Paizanis E, Hamon M, Lanfumey L. 2007. Hippocampal neurogenesis, depressive disorders, and antidepressant therapy. Neural Plast, 73754.

Paris D, Town T, Parker T, et al. 2000. Beta-Amyloid vasoactivity and proinflammation in microglia can be blocked by cGMP-elevating agents. Ann NY Acad Sci, 903:446-50.

Paris D, Town T, Parker TA, et al. 1999. Inhibition of Alzheimer's betaamyloid induced vasoactivity and proinflammatory response in microglia by a cGMP-dependent mechanism. Exp Neurol, 157:211-21.

Parks JK, Smith TS, Trimmer PA, et al. 2001. Neurotoxic Abeta peptides increase oxidative stress in vivo through NMDA-receptor and nitricoxide-synthase mechanisms, and inhibit complex IV activity and induce a mitochondrial permeability transition in vitro. $J$ Neurochem, 76:1050-6.

Pasquier F, Leys D. 1998. Blood pressure and Alzheimer's disease. Rev Neurol (Paris), 154:743-51.

Patil CS, Singh VP, Singh S, et al. 2004. Modulatory effect of the PDE-5 inhibitor sildenafil in diabetic neuropathy. Pharmacology, 72:190-5.

Pedersen JL, Galle TS, Kehlet H. 1998. Peripheral analgesic effects of ketamine in acute inflammatory pain. Anesthesiology, 89:58-66.

Percival MD, Yeh B, Falgueyret JP. 1997. Zinc dependent activation of cAMP-specific phosphodiesterase (PDE4A).Biochem Biophys Res Commun, 241:175-80.

Pezet S, McMahon SB. 2006. Neurotrophins: mediators and modulators of pain. Annu Rev Neurosci, 29:507-38.

Pitts WJ, Vaccaro W, Huynh T, et al. 2004. Identification of purine inhibitors of phosphodiesterase 7 (PDE7). Bioorg Med Chem Lett, 14:2955-8.

Polli JW, Kincaid RL. 1994. Expression of a calmodulin-dependent phosphodiesterase isoform (PDE1B1) correlates with brain regions having extensive dopaminergic innervation. J Neurosci, 14:1251-61.

Price JM, Hellermann A, Hellermann G, et al. 2004. Aging enhances vascular dysfunction induced by the Alzheimer's peptide beta-amyloid. Neurol Res, 26:305-11.

Prickaerts J, Sik A, van Staveren WC, et al. 2004. Phosphodiesterase type 5 inhibition improves early memory consolidation of object information. Neurochem Int, 45:915-28. 
Prickaerts J, Steinbusch HW, Smits JF, et al. 1997. Possible role of nitric oxide-cyclic GMP pathway in object recognition memory: effects of 7-nitroindazole and zaprinast. Eur J Pharmacol, 33:125-36.

Prickaerts J, van Staveren WC, Sik A, et al. 2002. Effects of two selective phosphodiesterase type 5 inhibitors, sildenafil and vardenafil, on object recognition memory and hippocampal cyclic GMP levels in the rat. Neuroscience, 113:351-61.

Prisant LM. 2006. Phosphodiesterase-5 inhibitors and their hemodynamic effects. Curr Hypertens Rep, 8:345-51.

Puzzo D, Palmeri A, Arancio O. 2006. Involvement of the nitric oxide pathway in synaptic dysfunction following amyloid elevation in Alzheimer's disease. Rev Neurosci, 17:497-523.

Puzzo D, Vitolo O, Trinchese F, et al. 2005. Amyloid-beta peptide inhibits activation of the nitric oxide/cGMP/cAMP-responsive element-binding protein pathway during hippocampal synaptic plasticity. J Neurosci, 25:6887-97.

Rall TW, Sutherland EW. 1958. Formation of a cyclic adenine ribonucleotide by tissue particles. $J$ Biol Chem, 232:1065-76.

Reed TM, Browning JE, Blough RI, et al. 1998. Genomic structure and chromosome location of the murine PDE1B phosphodiesterase gene. Mamm Genome, 9:571-6.

Renger JJ, Ueda A, Atwood HL, et al. 2000. Role of cAMP cascade in synaptic stability and plasticity: ultrastructural and physiological analyses of individual synaptic boutons in Drosophila memory mutants. J Neurosci, 20:3980-92.

Repaske DR, Corbin JG, Conti M, et al. 1993. A cyclic GMP-stimulated cyclic nucleotide phosphodiesterase gene is highly expressed in the limbic system of the rat brain. Neuroscience, 56:673-86.

Reyes-Irisarri E, Perez-Torres S, Mengod G. 2005. Neuronal expression of cAMP-specific phosphodiesterase 7B mRNA in the rat brain. Neuroscience, 132:1173-85.

Richter W. 2002. 3',5' Cyclic nucleotide phosphodiesterases class III: members, structure, and catalytic mechanism. Proteins, 46:278-86.

Roberson ED, Sweatt JD. 1996. Transient activation of cyclic AMPdependent protein kinase during hippocampal long-term potentiation. J Biol Chem, 271:30436-41.

Rose GM, Dunwiddie TV. 1986. Induction of hippocampal long-term potentiation using physiologically patterned stimulation. Neurosci Lett, 69:244-8.

Rose GM, Hopper A, De Vivo M, et al. 2005. Phosphodiesterase inhibitors for cognitive enhancement. Curr Pharm Des, 11:3329-34.

Rutten K, Prickaerts J, Hendrix M, et al. 2007. Time-dependent involvement of cAMP and cGMP in consolidation of object memory: studies using selective phosphodiesterase type 2, 4 and 5 inhibitors. Eur $J$ Pharmacol, 558:107-12.

Rutten K, Vente JD, Sik A, et al. 2005. The selective PDE5 inhibitor, sildenafil, improves object memory in Swiss mice and increases cGMP levels in hippocampal slices. Behav Brain Res, 164:11-16.

Rybalkin SD, Yan C, Bornfeldt KE, et al. 2003. Cyclic GMP phosphodiesterases and regulation of smooth muscle function.Circ Res, 93:280-91.

Saenz de Tejada I, Angulo J, Cuevas P, et al. 2001. The phosphodiesterase inhibitory selectivity and the in vitro and in vivo potency of the new PDE5 inhibitor vardenafil. Int J Impot Res, 13:282-90.

Sandeman R, Sandeman D. 2000. "Impoverished" and "enriched" living conditions influence the proliferation and survival of neurons in crayfish brain. J Neurobiol, 45:215-26.

Santarelli L, Saxe M, Gross C, et al. 2003. Requirement of hippocampal neurogenesis for the behavioral effects of antidepressants. Science, 301:805-9.

Sass P, Field J, Nikawa J, et al. 1986. Cloning and characterization of the high-affinity cAMP phosphodiesterase of Saccharomyces cerevisiae. Proc Natl Acad Sci USA, 83:9303-07.

Schenk D, Barbour R, Dunn W, et al. 1999. Immunization with amyloidbeta attenuates Alzheimer-disease-like pathology in the PDAPP mouse. Nature, 400:173-7.

Schmidt-Hieber C, Jonas P, Bischofberger J. 2004. Enhanced synaptic plasticity in newly generated granule cells of the adult hippocampus. Nature, 429:184-7.
Schultheiss D, Muller SV, Nager W, et al. 2001. Central effects of sildenafil (Viagra) on auditory selective attention and verbal recognition memory in humans: a study with event-related brain potentials. World J Urol, 19:46-50.

Schuman EM, Madison DV. 1991. A requirement for the intercellular messenger nitric oxide in long-term potentiation. Science, 254:1503-6.

Selkoe DJ. 1994. Normal and abnormal biology of the beta-amyloid precursor protein. Annu Rev Neurosci, 17:489-517.

Selkoe DJ. 2002. Alzheimer's disease is a synaptic failure. Science, 298:789-91.

Shakur Y, Takeda K, Kenan Y, et al. 2000. Membrane localization of cyclic nucleotide phosphodiesterase 3 (PDE3). Two N-terminal domains are required for the efficient targeting to, and association of, PDE3 with endoplasmic reticulum. J Biol Chem, 275:38749-61.

Shibuki K, Okada D. 1991. Endogenous nitric oxide release required for long-term synaptic depression in the cerebellum. Nature, 349:326-8.

Shieh PB, Hu SC, Bobb K, et al. 1998. Identification of a signaling pathway involved in calcium regulation of BDNF expression. Neuron, 20:727-40.

Shinozawa T, Bitensky MW. 1981. Purification and characteristics of photoreceptor light-activated guanosinetriphosphatase. Biochemistry, 20:7068-74.

Shors TJ, Miesegaes G, Beylin A, et al. 2001. Neurogenesis in the adult is involved in the formation of trace memories. Nature, 410:372-6.

Shors TJ, Townsend DA, Zhao M, et al. 2002. Neurogenesis may relate to some but not all types of hippocampal-dependent learning. Hippocampus, 12:578-84.

Shotwell SL. 1983. Cyclic adenosine 3':5'-monophosphate phosphodiesterase and its role in learning in Drosophila. J Neurosci, 3:739-47.

Singh N, Parle M. 2003. Sildenafil improves acquisition and retention of memory in mice. Indian J Physiol Pharmacol, 47:318-24.

Smith CC, Stanyer L, Betteridge DJ. 2004. Soluble beta-amyloid (A beta) 40 causes attenuation or potentiation of noradrenaline-induced vasoconstriction in rats depending upon the concentration employed. Neurosci Lett, 367:129-32.

Snyder JS, Hong NS, McDonald RJ, et al. 2005. A role for adult neurogenesis in spatial long-term memory. Neuroscience, 130:843-52.

Son H, Hawkins RD, Martin K, et al. 1996. Long-term potentiation is reduced in mice that are doubly mutant in endothelial and neuronal nitric oxide synthase. Cell, 87:1015-23.

Sonnenburg WK, Seger D, Kwak KS, et al. 1995. Identification of inhibitory and calmodulin-binding domains of the PDE1A1 and PDE1A2 calmodulin-stimulated cyclic nucleotide phosphodiesterases. $J$ Biol Chem, 270:30989-1000.

Souness JE, Aldous D, Sargent C. 2000. Immunosuppressive and antiinflammatory effects of cyclic AMP phosphodiesterase (PDE) type 4 inhibitors. Immunopharmacology, 47:127-62.

Southam E, Charles SL, Garthwaite J. 1996. The nitric oxide-cyclic GMP pathway and synaptic plasticity in the rat superior cervical ganglion. Br J Pharmacol, 119:527-32.

Stanciu M, Radulovic J, Spiess J. 2001. Phosphorylated cAMP response element binding protein in the mouse brain after fear conditioning: relationship to Fos production. Brain Res Mol Brain Res, 94:15-24.

Storozhuk MV, Balaban PM. 1990. Role of cyclic adenosine monophosphate in simple forms of plasticity in the edible snail. Neurosci Behav Physiol, 20:267-71.

Suhara T, Magrane J, Rosen K, et al. 2003. Abeta42 generation is toxic to endothelial cells and inhibits eNOS function through an Akt/GSK-3beta signaling-dependent mechanism. Neurobiol Aging, 24:437-51.

Susswein AJ, Katzoff A, Miller N, et al. 2004. Nitric oxide and memory. Neuroscientist, 10:153-62.

Sutherland EW. 1958. Fractionation and characterisation of a cyclic adenine ribonucleotide formed by tissue particles. J Biol Chem, 232:1077-91.

Suvarna NU, O'Donnell JM. 2002. Hydrolysis of N-methyl-D-aspartate receptor-stimulated cAMP and cGMP by PDE4 and PDE2 phosphodiesterases in primary neuronal cultures of rat cerebral cortex and hippocampus. J Pharmacol Exp Ther, 302:249-56. 
Taddei S, Virdis A, Ghiadoni L, et al. 2001. Age-related reduction of NO availability and oxidative stress in humans. Hypertension, 38:274-9.

Tao X, Finkbeiner S, Arnold DB, et al. 1998. Ca2+ influx regulates BDNF transcription by a CREB family transcription factor-dependent mechanism. Neuron, 20:709-26.

Taupin P. 2006. Neurogenesis in the adult central nervous system. $C R$ Biol, 329:465-75.

Thatcher GR, Bennett BM, Dringenberg HC, et al. 2004. Novel nitrates as NO mimetics directed at Alzheimer's disease. J Alzheimers Dis, 6(Suppl):S75-84.

Thatcher GR, Bennett BM, Reynolds JN. 2002. Nitric oxide mimetic molecules as therapeutic agents in Alzheimer's disease. Curr Alz Res, 2:171-82.

Thomas MK, Francis SH, Corbin JD. 1990. Characterization of a purified bovine lung cGMP-binding cGMP phosphodiesterase. J Biol Chem, 265:14964-70.

Thomason PA, Traynor D, Cavet G, et al. 1998. An intersection of the cAMP/ PKA and two-component signal transduction systems in Dictyostelium. Embo J, 17:2838-45.

Toward TJ, Smith N, Broadley KJ. 2004. Effect of phosphodiesterase-5 inhibitor, sildenafil (Viagra), in animal models of airways disease. Am J Respir Crit Care Med, 169:227-34.

Tran MH, Yamada K, Olariu A, et al. 2001. Amyloid- $\beta$ - peptide induces nitric oxide production in rat hippocampus: association with cholinergic dysfunction and amelioration by inducible nitric oxide synthase inhibitors. FASEB J, 15:1407-9.

Trinchese F, Liu S, Battaglia S, et al. 2004. Progressive age-related development of Alzheimer-like pathology in APP/PS1 mice. Ann Neurol, 55:801-14.

Troy CM, Rabacchi SA, Friedman WJ, et al. 2000. Caspase-2 mediates neuronal cell death induced by beta-amyloid. J Neurosci, 20:1386-92.

Tsukada S, Keino-Masu K, Masu M, et al. 2002. Activation of protein kinase A by nitric oxide in cultured dorsal root ganglion neurites of the rat, examined by a fluorescence probe, ARII. Neurosci Lett, 318:17-20.

Uthayathas S, Karuppagounder SS, Thrash BM, et al. 2007. Versatile effects of sildenafil: recent pharmacological applications.Pharmacol Rep, 59:150-63.

Van der Borght K, Havekes R, Bos T, et al. 2007. Exercise improves memory acquisition and retrieval in the Y-maze task: relationship with hippocampal neurogenesis. Behav Neuroscim, 121:324-34.

van Staveren WC, Glick J, Markerink-van Ittersum M, et al. 2002. Cloning and localization of the cGMP-specific phosphodiesterase type 9 in the rat brain. J Neurocytol, 31:729-41.

van Staveren WC, Steinbusch HW, Markerink-van Ittersum M, et al. 2004. Species differences in the localization of cGMP-producing and NOresponsive elements in the mouse and rat hippocampus using cGMP immunocytochemistry. Eur J Neurosci, 19:2155-68.

Vitolo OV, Sant'Angelo A, Costanzo V, et al. 2002. Amyloid $\beta$ peptide inhibition of the PKA/CREB pathway and long-term potentiation: reversibility by drugs that enhance cAMP signaling. Proc Natl Acad Sci USA, 99:13217-21.

Walsh DM, Klyubin I, Fadeeva JV, et al. 2002. Naturally secreted oligomers of amyloid beta protein potently inhibit hippocampal long-term potentiation in vivo. Nature, 416:535-9.

Walsh DM, Klyubin I, Shankar GM, et al. 2005. Certain inhibitors of synthetic amyloid beta-peptide (Abeta) fibrillogenesis block oligomerization of natural Abeta and thereby rescue long-term potentiation. $J$ Neurosci, 25:2455-62.

Waltereit R, Weller M. 2003. Signaling from cAMP/PKA to MAPK and synaptic plasticity. Mol Neurobiol, 27:99-106.

Wang H, Storm DR. 2003. Calmodulin-regulated adenylyl cyclases: crosstalk and plasticity in the central nervous system. Mol Pharmacol, 63:463-8.

Weeks JL, Blount MA, Beasley A, et al. 2005. Radiolabeled ligand binding to the catalytic or allosteric sites of PDE5 and PDE11. Methods Mol Biol, 307:239-62.
Weimann J, Ullrich R, Hromi J, et al. 2000. Sildenafil is a pulmonary vasodilator in awake lambs with acute pulmonary hypertension. Anesthesiology, 92:1702-12.

Weishaar RE, Kobylarz-Singer DC, Keiser J, et al. 1990. Subclasses of cyclic GMP-specific phosphodiesterase and their role in regulating the effects of atrial natriuretic factor. Hypertension, 15:528-40.

Wiesenfeld-Hallin Z. 1998. Combined opioid-NMDA antagonist therapies. What advantages do they offer for the control of pain syndromes? Drugs, 55:1-4.

Wirtz-Brugger F, Giovanni A. 2000. Guanosine 3',5'-cyclic monophosphate mediated inhibition of cell death induced by nerve growth factor withdrawal and beta-amyloid: protective effects of propentofylline. Neuroscience, 99:737-50.

Wiskott L, Rasch MJ, Kempermann G. 2006. A functional hypothesis for adult hippocampal neurogenesis: avoidance of catastrophic interference in the dentate gyrus. Hippocampus, 16:329-43.

Wu H, Zhou Y, Xiong ZQ. 2007. Transducer of regulated CREB and late phase long-term synaptic potentiation. FEBS J, 274:3218-23.

Wu ZL, Thomas SA, Villacres EC, et al. 1995. Altered behavior and longterm potentiation in type I adenylyl cyclase mutant mice. Proc Natl Acad Sci USA, 92:220-4.

Wunder F, Tersteegen A, Rebmann A, et al. 2005. Characterization of the first potent and selective PDE9 inhibitor using a cGMP reporter cell line. Mol Pharmacol, 68:1775-81.

Xie Z, Wei M, Morgan TE, et al. 2002. Peroxynitrite mediates neurotoxicity of amyloid beta-peptide 1-42- and lipopolysaccharide-activated microglia. J Neurosci, 22:3484-92.

Yamada K, Noda Y, Hasegawa T, et al. 1996. The role of nitric oxide in dizocilpine-induced impairment of spontaneous alternation behavior in mice. J Pharmacol Exp Ther, 276:460-6.

Yan C, Bentley JK, Sonnenburg WK, et al. 1994. Differential expression of the $61 \mathrm{kDa}$ and $63 \mathrm{kDa}$ calmodulin-dependent phosphodiesterases in the mouse brain. J Neurosci, 14:973-84.

Yanaka N, Kotera J, Ohtsuka A, et al. 1998. Expression, structure and chromosomal localization of the human cGMP-binding cGMP-specific phosphodiesterase PDE5A gene. Eur J Biochem, 255:391-9.

Yin JC, Wallach JS, Del Vecchio M, et al. 1994. Induction of a dominant negative CREB transgene specifically blocks long-term memory in Drosophila. Cell, 79:49-58.

Yoshimura H, Kato N. 2000. Diverse roles of intracellular cAMP in early synaptic modifications in the rat visual cortex. J Physiol, 3:417-26.

Yovell Y, Kandel ER, Dudai Y, et al. 1987. Biochemical correlates of shortterm sensitization in Aplysia: temporal analysis of adenylate cyclase stimulation in a perfused-membrane preparation. Proc Natl Acad Sci USA, 84:9285-9.

Yu J, Wolda SL, Frazier AL, et al. 1997. Identification and characterisation of a human calmodulin-stimulated phosphodiesterase PDE1B1. Cell Signal, 9:519-29.

Zhang L, Zhang Z, Zhang RL, et al. 2006a. Tadalafil, a long-acting type 5 phosphodiesterase isoenzyme inhibitor, improves neurological functional recovery in a rat model of embolic stroke. Brain Res, 1118:192-8.

Zhang R, Wang Y, Zhang L, et al. 2002. Sildenafil (Viagra) induces neurogenesis and promotes functional recovery after stroke in rats. Stroke, 33:2675-80.

Zhang RL, Zhang Z, Zhang L, et al. 2006b. Delayed treatment with sildenafil enhances neurogenesis and improves functional recovery in aged rats after focal cerebral ischemia. $J$ Neurosci Res, 83:1213-19.

Zhao M, Momma S, Delfani K, et al. 2003. Evidence for neurogenesis in the adult mammalian substantia nigra. Proc Natl Acad Sci USA, 100:7925-30.

Zhong Y, Budnik V, Wu CF. 1992. Synaptic plasticity in Drosophila memory and hyperexcitable mutants: role of cAMP cascade. J Neurosci, 12:644-51.

Zhong Y, Wu CF. 1991. Altered synaptic plasticity in Drosophila memory mutants with a defective cyclic AMP cascade. Science, 251:198-201 
Zhuo M, Hu Y, Schultz C, et al. 1994. Role of guanylyl cyclase and cGMP-dependent protein kinase in long-term potentiation. Nature, 368:635-9.

Zhuo M, Small SA, Kandel ER, et al. 1993. Nitric oxide and carbon monoxide produce activity-dependent long-term synaptic enhancement in the hippocampus. Science, 260:1946-50.

Ziegler JW, Ivy DD, Fox JJ, et al. 1995. Dipyridamole, a cGMP phosphodiesterase inhibitor, causes pulmonary vasodilation in the ovine fetus. Am J Physiol, 269:H473-9.
Zoraghi R, Bessay EP, Corbin JD, et al. 2005. Structural and functional features in human PDE5A1 regulatory domain that provide for allosteric cGMP binding, dimerization, and regulation. $J$ Biol Chem, 280:12051-63.

Zou LB, Yamada K, Tanaka T, et al. 1998. Nitric oxide synthase inhibitors impair reference memory formation in a radial arm maze task in rats. Neuropharmacology, 37:323-30. 
